\title{
Food pyramid for subjects with chronic pain: foods and dietary constituents as anti-inflammatory and antioxidant agents
}

\author{
Mariangela Rondanelli ${ }^{1}$, Milena Anna Faliva ${ }^{1}$, Alessandra Miccono ${ }^{2}$, Maurizio Naso ${ }^{1}$, Mara Nichetti ${ }^{1}$, \\ Antonella Riva ${ }^{3}$, Fabio Guerriero ${ }^{4}$, Manuela De Gregori ${ }^{5,6}$, Gabriella Peroni ${ }^{1}$ and Simone Perna ${ }^{1 *}$ \\ ${ }^{1}$ University of Pavia, Department of Public Health, Experimental and Forensic Medicine, Section of Human Nutrition, \\ Endocrinology and Nutrition Unit, Azienda di Servizi alla Persona, Pavia, Italy \\ ${ }^{2}$ Department of Clinical Sciences, Faculty of Medicine and Surgery, University of Milan, Milan, Italy \\ ${ }^{3}$ RED Indena SpA, Viale Ortles 12, 20139 Milan, Italy \\ ${ }^{4}$ Department of Internal Medicine, Section of Geriatrics and Gerontology, University of Pavia, Azienda di Servizi alla Persona \\ "Istituto Santa Margherita", Pavia, Italy \\ ${ }^{5}$ Pain Therapy Service, Fondazione IRCCS Policlinico San Matteo, Pavia, Italy \\ ${ }^{6}$ SIMPAR group (Study in Multidisciplinary PAin Research), Parma, Italy
}

\section{Abstract}

Emerging literature suggests that diet constituents may play a modulatory role in chronic pain (CP) through management of inflammation/ oxidative stress, resulting in attenuation of pain. We performed a narrative review to evaluate the existing evidence regarding the optimum diet for the management of $\mathrm{CP}$, and we built a food pyramid on this topic. The present review also describes the activities of various natural compounds contained in foods (i.e. phenolic compounds in extra-virgin olive oil (EVO)) listed on our pyramid, which have comparable effects to drug management therapy. This review included 172 eligible studies. The pyramid shows that carbohydrates with low glycaemic index should be consumed every day (three portions), together with fruits and vegetables (five portions), yogurt (125 ml), red wine (125 ml) and EVO; weekly: legumes and fish (four portions); white meat, eggs and fresh cheese (two portions); red or processed meats (once per week); sweets can be consumed occasionally. The food amounts are estimates based on nutritional and practical considerations. At the top of the pyramid there is a pennant: it means that CP subjects may need a specific customised supplementation (vitamin $\mathrm{B}_{12}$, vitamin $\mathrm{D}, n-3$ fatty acids, fibre). The food pyramid proposal will serve to guide dietary intake with to the intent of alleviating pain in CP patients. Moreover, a targeted diet can also help to solve problems related to the drugs used to combat CP, i.e. constipation. However, this paper would be an early hypothetical proposal due to the limitations of the studies.

\section{Key words: Chronic pain: Nutrients: Inflammation: Food pyramid: Constipation: Opioids: Antioxidants}

\section{Introduction}

A food-specific diet, possibly associated with dietary supplements, can provide helpful support for patients suffering from chronic pain ${ }^{(1)}$. A high number of chronic pain subjects have elevated levels of pro-inflammatory cytokines in blood and tissues $^{(2)}$.

Regardless of underlying causes of pain, inflammation is the primary means of alert that calls into action the cells responsible for surveillance and protection, set in motion to limit tissue damage $^{(3)}$. It is a normal biological process in response to tissue injury, to a microbial infection, and to a chemical irritation ${ }^{(4)}$.

Inflammation is caused by the migration of immune cells from the blood vessels and the release of mediators in the damage site ${ }^{(5)}$. This process is followed by the recruitment of inflammatory cells, release of reactive oxygen species and proinflammatory cytokines, in order to eliminate pathogens and repair damaged tissue ${ }^{(6)}$. In general, normal inflammation is rapid and self-limiting, but prolonged inflammation can cause various chronic painful disorders ${ }^{(7)}$.

If the acute inflammatory phase does not eliminate the pathogen resolving inflammation, the inflammatory process continues and develops into a chronic condition, associated with chronic pain ${ }^{(8)}$.

Inflammation represents a cause of nociceptive pain ${ }^{(2)}$ and osteoarthrosis (OA) is one of the most common syndromes ${ }^{(9)}$ causing limited joint motion, pain and disability. In Europe osteoarthritis affects over 40 million adults, according to the European League Against Rheumatism (EULAR) ${ }^{(10)}$. OA patients often cannot reach an adequate pain relief with drugs

Abbreviations: ALA, $\alpha$-linolenic acid; COX, cyclo-oxygenase; CRP, C-reactive protein; EVO, extra virgin olive oil; LAO, long-acting specific opioid formulation; MCP-1, monocyte chemotactic protein-1; NMDA, N-methyl-d-aspartate; NSAID, non-steroidal anti-inflammatory drug; OA, osteoarthrosis; OIC, opioid-induced constipation; SIRT1, sirtuin-1; TLR, Toll-like receptor; TRP, transient receptor potential.

* Corresponding author: Dr Simone Perna, email simoneperna@hotmail.it 
(non-steroidal anti-inflammatory drugs (NSAID) and weak opioids) and/or develop severe side effects. Risk of developing OA is largely related to lifestyle factors like diet and physical activity. Weight control and maintaining a BMI within the normal range (between 18.5 and $25 \mathrm{~kg} / \mathrm{m}^{2}$ ) supports the analgesic and anti-inflammatory therapies $^{(11)}$. Moreover, adipose tissue releases inflammatory molecules, such as leptin and cytokines, whose release can be reduced or even suppressed by the decrease of fat mass ${ }^{(12)}$.

Finally, a recent study by Emery et al. ${ }^{(13)}$ showed that dietary intake of foods with anti-inflammatory effects (sea-food and plant proteins) mediates the relationship of body fat to body pain in men and women.

Adequate intake of specific foods and nutrients can effectively improve the inflammation state and oxidative stress ${ }^{(14)}$ resulting also in chronic pain management ${ }^{(1,15)}$.

Although inflammation and oxidative stress are certainly the main factors determining chronic pain, other factors can also contribute significantly to chronic pain, such as psychosocial factors, biomechanical factors (processes of continuous muscle contraction favour microtrauma and the formation of trigger points), other causes of neural pain processing, etc. Various nutrients have been shown to produce an antinociceptive effect in animal models of neuropathic and inflammatory pain; in particular, it is known that $\mathrm{Mg}$ is a physiological antagonist of the $N$-methyl-D-aspartate (NMDA) receptor ion channel, and that the NMDA receptor plays a key role in central sensitisation, the primary mechanism through which Mg produces its analgesic effect, is believed to be a blockade of the NMDA receptor in the spinal cord ${ }^{(10)}$.

In addition, $\mathrm{Mg}$ blocks $\mathrm{Ca}$ channels and modulates $\mathrm{K}$ channels. The activation of the NO pathway could have an important role in the antinociceptive effects of systemic magnesium sulfate in the somatic (but not the visceral) model of inflammatory pain.

In clinical trials, most authors confirmed that $\mathrm{Mg}$ reduces opioid consumption and alleviates postoperative pain scores while not increasing the risk of side effects after opioids ${ }^{(17)}$

Given this background, the aim of the present review was to evaluate the existing evidence regarding optimum diet therapy for the management of chronic pain, and to acknowledge the assumption that lower markers of inflammation and oxidative stress correspond with lower chronic pain.

\section{Methods}

This narrative review was performed following these steps ${ }^{(18)}$ :

(1) Configuration of a working group: three operators skilled in clinical nutrition (one acting as a methodological operator and two participating as clinical operators).

(2) Formulation of the review question on the basis of considerations made in the abstract: 'the state of the art on management of inflammation and oxidative stress through dietary approach in chronic pain'.

(3) Identification of relevant studies: a research strategy was planned on PubMed (Public MedLine run by the National Center of Biotechnology Information (NCBI) of the National Library of Medicine of Bethesda, USA) as follows:

(a) Definition of the keywords (chronic pain, foods, inflammation, oxidative stress, nutrients), allowing the definition of the interest field of the documents to be searched, grouped in inverted commas (... ') and used separately or in combination;

(b) Use of: the Boolean (a data type with only two possible values: true or false) AND operator, that allows the establishment of logical relations among concepts;

(c) Research modalities: advanced search;

(d) Limits included: time limits: papers published in the last 20 years; languages: English;

(e) Manual search performed by the senior researchers experienced in clinical nutrition through the reviewing of reviews and individual articles on the management of inflammation and oxidative stress by a dietary approach in chronic pain published in journals qualified in the Index Medicus.

(4) Analysis and presentation of outcomes: the data extrapolated from the 'reviewed studies' were collated in tables; in particular, for each study we specified the author and year of publication, study characteristics and results.

(5) The analysis was carried out in the form of a narrative review of the reports. We evaluated, as suitable for the narrative review, humans and in vitro or animal model studies of any design that considered:

(a) the relevance of foods or nutrients for chronic pain management;

(b) mechanism-based reasoning that showed a decrease of some inflammatory markers.

The keywords considered and the kinds of studies chosen for specific foods are as below.

Water

This research was carried out based on the keywords: 'chronic pain' AND 'inflammation' AND 'oxidative stress' AND 'water' OR 'hydratation'; three articles were sourced: two human in vivo studies and one cross-over study.

\section{Fruits and vegetables}

This research was carried out based on the keywords: 'chronic pain' AND 'inflammation' AND 'oxidative stress' AND 'fruit' OR 'vegetables'; ten articles were sourced: one randomised controlled study, two narrative reviews, one cross-over study, two clinical trials, three cross-sectional studies and one placebocontrolled trial.

\section{Carbohydrates with low glycaemic index/load}

This research was carried out based on the keywords: 'chronic pain' AND 'inflammation' AND 'oxidative stress' AND ‘carbohydrates'; five articles were sourced: two randomised controlled studies, two narrative reviews and one cross-over study.

\section{Olive oil and olives}

This research was carried out based on the keywords: 'chronic pain' AND 'inflammation' AND 'oxidative stress' AND 'olive oil'; twenty-four articles were sourced: four randomised controlled trial, twelve narrative reviews, one parallel study, one clinical trial, three in vitro studies and three clinical studies. 


\section{Red meat, white meat and fish}

This research was carried out based on the keywords: 'chronic pain' AND 'inflammation' AND 'oxidative stress' AND 'meat' AND 'fish'; five articles were sourced: one cohort study, one narrative review, one prospective study, one investigation and one animal model study.

\section{Legumes}

This research was carried out based on the keywords: 'chronic pain' AND 'inflammation' AND 'oxidative stress' AND 'legumes' AND 'soybeans'; six articles were sourced: one meta-analysis, one narrative review, one cross-over study, one placebocontrolled trial, one in vitro study and one animal study.

\section{Yogurt}

This research was carried out based on the keywords: 'chronic pain' AND 'inflammation' AND 'oxidative stress' AND 'yogurt' AND 'probiotics' OR 'fermented milk'; eleven articles were sourced: one randomised controlled trial, eight narrative reviews, one cross-over study and one animal model study.

\section{Oil seeds}

This research was carried out based on the keywords: 'chronic pain' AND 'inflammation' AND 'oxidative stress' AND 'oil seeds'; fourteen articles were sourced: three meta analyses of other studies, one prospective study, one placebo-controlled trial, one systematic review, four cross-over studies and four animal model studies.

\section{Spices}

This research was carried out based on the keywords: 'chronic pain' AND 'inflammation' AND 'oxidative stress' AND 'spices'; eight articles were sourced: one meta-analysis, one book chapter, two narrative reviews, one randomised controlled trial and three animal model studies.

\section{Eggs}

This research was carried out based on the keywords: 'chronic pain' AND 'inflammation' AND 'oxidative stress' AND 'egg'; four articles were sourced: one randomised controlled trial, one narrative review and two in vitro studies.

\section{Cheeses}

This research was carried out based on the keywords: 'chronic pain' AND 'inflammation' AND 'oxidative stress' AND 'cheeses' AND 'dairy product'; seven articles were sourced: three crossover studies, one longitudinal study, two reviews and one comparative study.

\section{Red wine}

This research was carried out based on the keywords: 'chronic pain' AND 'inflammation' AND 'oxidative stress' AND 'red wine' AND 'alcohol'; twenty-six articles were sourced. Among them, one survey, eight narrative reviews, one systematic review, three cross-over studies, two observational studies, two in vitro studies, eight animal model studies and one CONSORT study were selected and discussed.

\section{Homemade sweets}

This research was carried out based on the keywords: 'chronic pain' AND 'inflammation' AND 'oxidative stress' AND 'sweets' OR 'sugar'; six articles were sourced: three cross-sectional studies, two narrative reviews and one randomised controlled trial.

\section{Vitamin D}

This research was carried out based on the keywords: 'chronic pain' AND 'inflammation' AND 'oxidative stress' AND 'vitamin D' OR '25 hydroxyvitamin D' OR '25(OH)D'; seven articles were sourced. Among them, one prospective study, four narrative reviews and two longitudinal studies were selected and discussed.

\section{Vitamin $B_{12}$}

This research was carried out based on the keywords: 'chronic pain' AND 'inflammation' AND 'oxidative stress' AND 'vitamin B12' OR 'cobalamin' OR 'cyanocobalamin'; three articles were sourced, in particular one randomised controlled trial and two animal studies.

\section{n-3 PUFA}

This research was carried out based on the keywords: 'chronic pain' AND ‘inflammation' AND 'oxidative stress' AND 'omega 3' OR ' $\Omega 3$ ' OR 'polyunsaturated fatty acids'; six articles were sourced: one prospective study, two narrative reviews and three animal model studies.

\section{Fibre}

This research was carried out based on the keywords: 'chronic pain' AND 'inflammation' AND 'oxidative stress' AND 'fiber'; two articles were sourced: one position paper and one narrative review.

\section{Role of dietary fibre in opioid-induced constipation}

This research was carried out based on the keywords: 'chronic pain' AND ‘inflammation' AND 'oxidative stress' AND 'constipation' AND 'fiber' AND 'opioids'; seven articles were sourced: two narrative reviews, one book chapter, two animal model studies, one position paper and one observational study.

\section{Micronutrients: zinc and selenium}

This research was carried out based on the keywords: 'chronic pain' AND 'inflammation' AND 'oxidative stress' AND 'zinc' AND 'selenium'; eighteen articles were sourced: two clinical human studies, eleven reviews and position paper and five animal studies. 


\section{Levels of evidence}

Moreover, levels of evidence, as defined in the EMBC Levels of Evidence Working Group (Oxford Centre for Evidence-Based Medicine), have been added in the tables, in order to better clarify the quality of the studies included ${ }^{(19)}$.

The key to the levels of evidence were: level $1=$ systematic review of randomised trials or $n$-of- 1 trial; level $2=$ randomised trial (of good methodological quality) or observational study with dramatic effect; level $3=$ non-randomised controlled cohort/follow-up study; level $4=$ case-series, case-control studies, or historically controlled studies; level 5=mechanismbased reasoning. The levels of evidence were considered from the viewpoint that reducing inflammation led to an improvement of chronic pain, which was the endpoint.

\section{Results}

This review included 172 eligible studies and the dedicated flow-chart is shown in Fig. 1.

In online Supplementary Tables S1-S18 the studies considered for the review are summarised.

Moreover, it is therefore thought to represent graphically, in a simple and intuitive way, what should be proper nutrition for the chronic pain patient, specifying the quality and amount of food, in order to counter the states of chronic inflammation and increased oxidative stress.

This pyramid (Fig. 2) is divided into:

(a) foods that should be consumed daily;

(b) foods that must be consumed 1, 2 or 4 times per week;

(c) foods to be eaten occasionally.

The food amounts are estimates based on nutritional and practical considerations.

The pennant at the top of the pyramid means that chronic pain subjects need a specific customised dietary supplementation with vitamin $\mathrm{B}_{12}$, vitamin $\mathrm{D}, n-3$ fatty acids and fibre.

\section{Water}

Water is the essential constituent of the human organism and is indispensable for the conduct of all physiological processes and biochemical reactions. Adequate water intake depends on many factors, such as age, sex, environmental conditions, activity level and level of sweating. It is helpful to drink about 1.5-2 litres daily, as specified in the latest revision of the Guidelines for Healthy Eating in $2003^{(20)}$.

Two recent studies have analysed the effects of dehydration on pain in healthy subjects by the 'cold pressor test' (CPT). Hypohydration can change the cerebrovascular response to $\mathrm{CPT}^{(21)}$, resulting in increased pain sensitivity ${ }^{(22)}$. The mechanism underpinning the increase in pain perception due to hypohydration is unclear: the key factor causing the increase in pain centre activity is activated by the subjective feeling of thirst within a multimodal network designed to detect negative sensory inputs. An alternative, or possibly related, explanation of the increase in pain perception induced by hypohydration involves cortisol, as blood cortisol concentrations are increased by hypohydration. Pain perception is linked directly to cortisol and may be indirectly linked by cortisol's involvement in key pain regulation processes such as regulation of the immune system and testosterone production, which may reduce pain by suppressing activity in the thalamus and middle frontal; therefore, cortisol may increase pain perception by lowering testosterone ${ }^{(22)}$.

Osteopathic treatment improves pain symptoms and the effect may be greater in euhydration than hypohydration ${ }^{(23)}$

Online supplementary Table S1 summarises the studies investigating the role of water intake in chronic pain subjects.

In conclusion, hydration status is significantly correlated with pain; therefore, water is at the base of the pyramid.

\section{Fruits and vegetables}

Assmann et al. ${ }^{(24)}$ underline that, during midlife, the adherence to a healthy diet that provides micronutrients, fibre and antioxidants while regulating energy intake may help to promote healthy ageing. Also the Dietary Approaches to Stop Hypertension (DASH) diet exerts an important role in preventing inflammatory disease, because of its low saturated fat content and emphasis on eating an abundance of fruits and vegetables.

Consumption of fruits and vegetables, which contain many vitamins, minerals and antioxidants, is inversely associated with inflammation and oxidative stress in adults: the higher the consumption of vegetables, the lower the occurrence of inflammation and oxidative stress ${ }^{(25-28)}$ : Miller et al. ${ }^{(25)}$ evaluated the difference between a typical American diet and a DASH diet (rich in fruit and vegetables) and they observed that the second one reduced oxidative stress (urinary isoprostanes) yet increased antibodies to oxidation of LDL.

Some researchers have focused their attention on the decrease in C-reactive protein (CRP) levels associated with diets rich in fruits and vegetables ${ }^{(29-31)}$. These three studies reached their conclusions based on FFQ.

Holt et $a{ }^{\left({ }^{(32)}\right.}$ investigated this association in adolescents, confirming the results obtained for adults: the consumption of fruit and vegetables was inversely correlated with markers of inflammation (CRP, IL-6, TNF- $\alpha$ and 15-keto-dihydro-PGF2 $\alpha$ metabolite) and oxidative stress (urinary 8-iso PG F2 $\alpha$, an F2-isoprostane) tested with a FFQ.

The inflammation reduction is secondary to the content in fruits and vegetables of high amounts of fibre, micronutrients (such as vitamins $\mathrm{C}$ and $\mathrm{E}$, and folate) and phytochemicals (such as carotenoids, phenolics, isoflavones and indoles). In addition, intake of fruits and vegetables stimulates the production of butyrate, produced by bacterial fermentation of dietary fibre in the colon, which reduces inflammation of the mucosa by decreasing the activity of $\mathrm{NF}-\kappa \mathrm{B}$ in colonic cells in patients with ulcerative colitis ${ }^{(33)}$.

Flavonoids (in citrus fruits, apples, berries, tomatoes, fennel, cauliflower, etc.) appear to be involved in maintaining the sealing of intercellular junctions, which are part of the main determinants of the intestinal barrier function ${ }^{(34)}$.

Online Supplementary Table S2 summarises the studies that investigate the relationship between intake of fruits and vegetables and imbalance between antioxidant capacity and oxidative stress and pro/anti-inflammatory markers.

In conclusion, the literature is sufficient to demonstrate that fruit and vegetable consumption is inversely associated with 

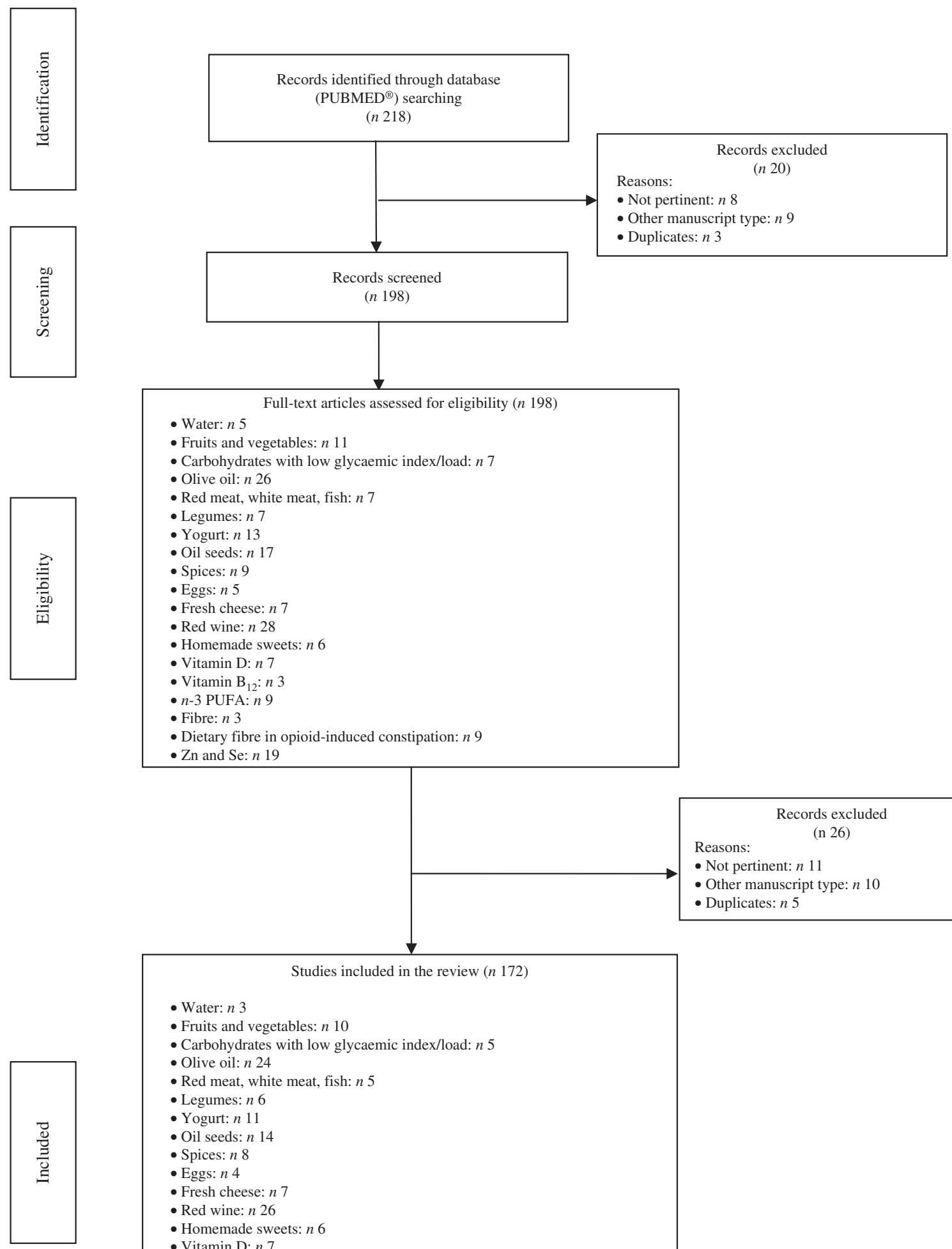

- Fruits and vegetables: $n 11$

- Carbohydrates with low glycaemic index/load: $n 7$

- Olive oil: $n 26$

- Red meat, white meat, fish: $n 7$

- Legumes: $n 7$

- Yogurt: $n 13$

- Oil seeds: $n 17$

- Spices: $n 9$

- Eggs: $n 5$

- Fresh cheese: $n 7$

- Red wine: $n 28$

- Homemade sweets: $n 6$

- Vitamin D: $n 7$

- Vitamin $\mathrm{B}_{12}: n 3$

- $n$-3 PUFA: $n 9$

- Fibre: $n 3$

- Dietary fibre in opioid-induced constipation: $n 9$

- Zn and Se: $n 19$

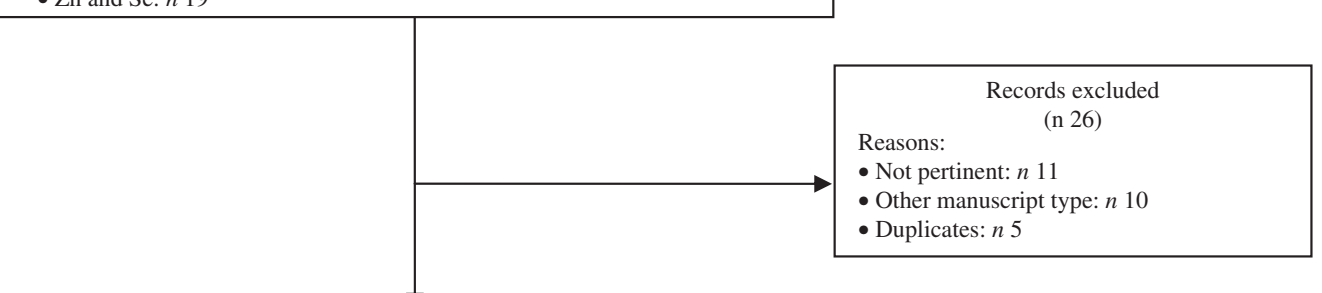

Studies included in the review ( $n$ 172)

- Water: $n 3$

- Fruits and vegetables: $n 10$

- Carbohydrates with low glycaemic index/load: $n 5$

- Olive oil: $n 24$

- Red meat, white meat, fish: $n 5$

- Legumes: $n 6$

- Yogurt: $n 11$

- Oil seeds: $n 14$

- Spices: $n 8$

- Eggs: $n 4$

- Fresh cheese: $n 7$

- Red wine: $n 26$

- Homemade sweets: $n 6$

- Vitamin D: $n 7$

- Vitamin $\mathrm{B}_{12}: n 3$

- $n$-3 PUFA: $n 6$

- Fibre: $n 2$

- Dietary fibre in opioid-induced constipation: $n 7$

- Zn and Se: $n 18$

Fig. 1. Flow diagram of the study. 


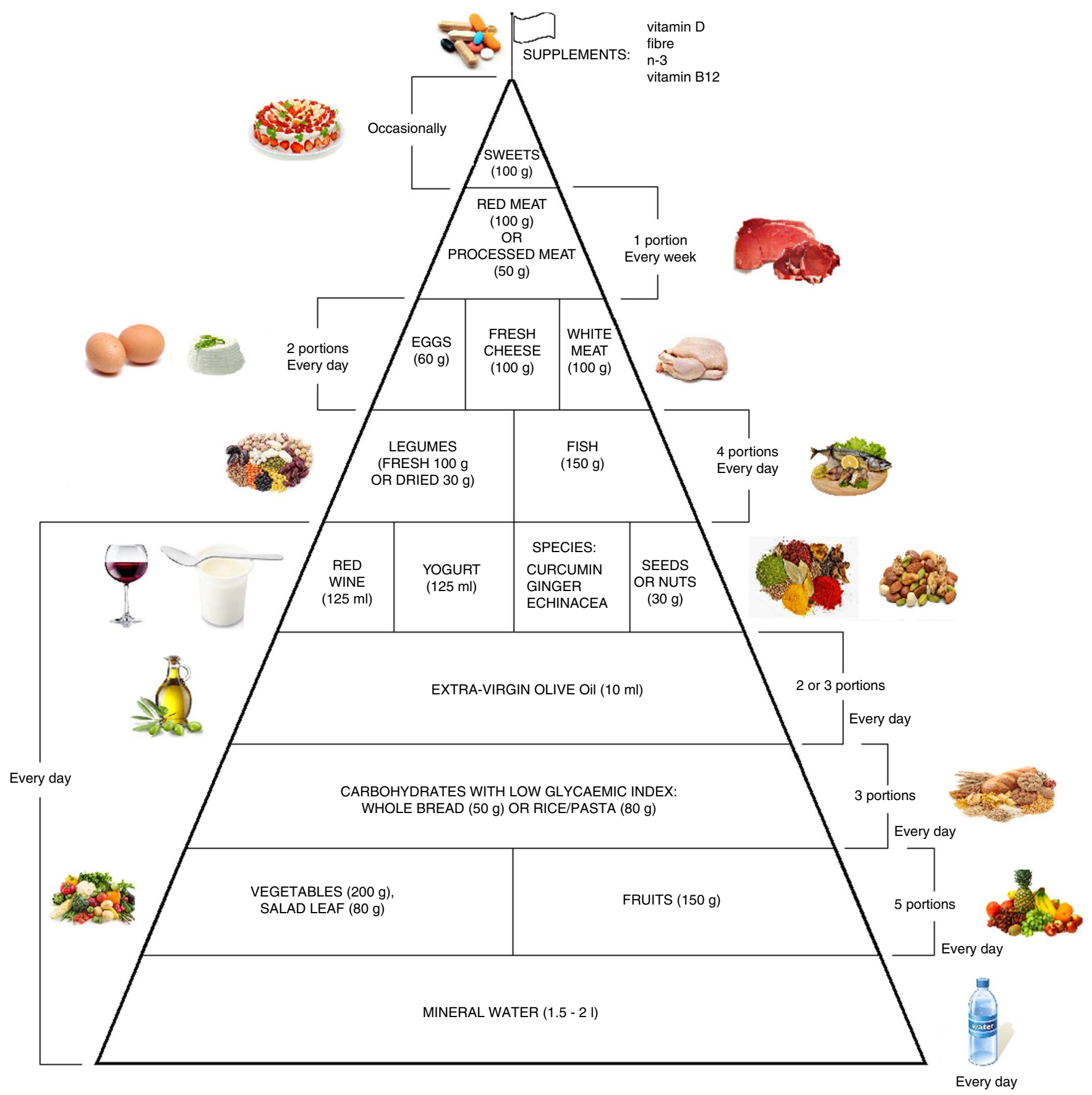

Fig. 2. Food pyramid for the dietary management of chronic pain. It is recommended to take whole grains daily (three portions of lower-glycaemic index grains, for example whole rice or Basmati rice or Doongara rice or rolled oats).

pro-inflammatory cytokines and reactive oxygen species, secondary to inflammation and oxidative stress in adults. In order to reduce pro-inflammatory cytokines and reactive oxygen species, a daily intake of five portions of fruits and vegetables is recommended.

\section{Carbohydrates with low glycaemic index/load}

The consumption of high-glycaemic index food may contribute to oxidative stress and low-grade inflammation, both in acute and chronic pain, through changes in NF- $\mathrm{KB}^{(35)}$. An excessive postprandial glucose excursion causes the generation of $\mathrm{NO}$, which in turn combines with superoxide to produce peroxynitrite, a potent and long-lived pro-oxidant molecule ${ }^{(36)}$.

Fardet ${ }^{(37)}$ analysed the components of whole grains that have low glycaemic index, and concluded that these foods are rich in various bioactive compounds (polyphenols, phytic acid and lignin) with anti-inflammatory properties, including the reduction of free radicals and the activation of antioxidant enzymes, but the author underlined the necessity of other studies to determine the mechanisms involved. 
These associations were further confirmed in a recent study, which compared a low-glycaemic index with a high-glycaemic index diet: in this study patients were randomised to different $\operatorname{diets}^{(38)}$. A dietary approach with foods with a low glycaemic index is more effective in regard to the reduction of chronic inflammation, taking as the first outcome high-sensitivity CRP, whereas glycaemic peaks are one of the main causes of oxidative stress $^{(38)}$. In line with this, Ebbeling et al. ${ }^{(39)}$ observed lower concentrations of CRP following a low-glycaemic index diet compared with a higher-glycaemic index diet.

Online Supplementary Table S3 summarises the studies investigating the relationship between carbohydrate intake with a low glycaemic index $(<70)$ and imbalance between antioxidant capacity and oxidative stress and pro/anti-inflammatory markers, all conditions present in chronic pain subjects.

In conclusion, it is recommended to take daily whole grains (three portions of whole grains, for example whole rice or Basmati rice or Doongara rice or rolled oats) in order to lower glycaemic index and load of the diet.

\section{Olive oil and olives}

The main source of lipid intake in the Mediterranean diet is represented by extra virgin olive oil (EVO). The intake of these lipids (rich in MUFA) has been recognised as an important factor contributing to the positive health profile characteristic of the Mediterranean population, because they have anti-inflammatory, antimicrobial and antioxidant activity ${ }^{(40)}$.

The high concentration of MUFA and many bioactive compounds (such as polyphenols) are mainly responsible for its anti-inflammatory properties; other seed oils do not have the same health benefits as EVO, as demonstrated by the study of Harper et al. ${ }^{(41)}$ in which a supplementation of $\alpha$-linolenic acid (ALA) of flaxseed oil did not decrease CVD risk, and by the study of Aguilera et $a l^{(42)}$ in which a supplementation of sunflower-seed oil did not protect as olive oil ${ }^{(41,42)}$.

Lignans are the main components of the phenolic fraction of polyphenols in $\mathrm{EVO}^{(43)}$ and the main representatives are acetoxipinoresinol and pinoresinol.

Despite the different concentrations among different EVO oils, lignans are present in greater quantities than other phenolic components, in a range between 0.65 and $99.97 \mathrm{mg} / \mathrm{kg}^{(44)}$. The antiinflammatory properties of bioactive compounds of EVO could explain why the incidence of cancer and heart diseases is lower in the Mediterranean basin than in other geographic areas ${ }^{(45)}$.

Also, nutraceutical properties of EVO have been attributed to secoiridoids, such as oleuropein and its derivatives, the main alcohols 3,4-dihydroxyphenyl ethanol, also known as hydroxytyrosol and the $p$-hydroxyphenyl ethanol or tyrosol ${ }^{(40,46)}$.

In addition, these phenolic components from EVO, in many preclinical models of disease, show a great variety of beneficial effects, mainly related to their antioxidant activity ${ }^{(47-52)}$. Oleuropein has an anti-inflammatory effect thanks to the increase in NO production, in macrophages and inhibiting lipoxygenase activity and the production of leukotriene $\mathrm{B} 4^{(47-51)}$.

Moreover, oleuropein and hydroxytyrosol have vasodilator properties, anti-inflammatory activity and an anti-aggregating action on platelets ${ }^{(47-50,53,54)}$.
Decarboxymethyl-aglycone ligstroside or oleocanthal is a phenolic compound that mimics the inhibitory action of cyclooxygenase (COX) by the NSAID ibuprofen, as a natural NSAID $^{(55)}$.

Oleocanthal was identified in the secoiridoid fraction of EVO phenolic compounds ${ }^{(54)}$ and described as the compound responsible for oropharyngeal irritation associated with EVO intake ${ }^{(56)}$, perceptually similar to the irritation caused by ibuprofen ${ }^{(57,58)}$.

Subsequently, in a study by Beauchamp et al. ${ }^{(55)}$, oleocanthal showed dose-dependent inhibition of the inflammatory enzymes COX-1 and COX-2 more powerful, in equimolar concentrations, as compared with ibuprofen.

Obviously the fruit olive (Olea europaea), from which EVO is derived by cold pressing, has significant anti-inflammatory and antinociceptive activities due to the presence of many phenolic compounds (among these the most important are hydroxytyrosol and tyrosol) ${ }^{(59)}$. Takeda et al. ${ }^{(60)}$ treated a group of twenty-five individuals with early-stage knee osteoarthritis: hydroxytyrosol was effective in improving pain in gonarthrosis, measuring with the Japanese Orthopedic Association score and a visual analogue scale score compared with the placebo group. Moreover, olive pits have cholinergic activity as demonstrated by the study of Cortés Castell et al. ${ }^{(61)}$ who determined the effect of a polyphenolic extract from olive pits on the development of the nervous system as well as its effect on pain induced by the neurotoxin kainic acid, taking the zebrafish as the animal model. Olive fruits are rich in dietary fibre and, overall, one of the most important compound is ferulic acid that has antiinflammatory activity ${ }^{(62)}$. Suntar et al. $^{(63)}$ have evaluated the anti-inflammatory and anti-nociceptive properties of leaves and fruits of Olea europaea L. (family Oleaceae) and the results revealed that ethanolic extract did not show a significant antiinflammatory or analgesic activity, whereas the $n$-hexane extract displayed $12 \cdot 7-27.8 \%$ inhibition on the carrageenaninduced hind paw oedema model at the $400 \mathrm{mg} / \mathrm{kg}$ dose ${ }^{(63)}$.

Online Supplementary Table S4 summarises the studies investigating the relationship between EVO intake and imbalance between antioxidant capacity, oxidative stress and pro/ anti-inflammatory markers, which represent conditions present in chronic pain subjects.

In conclusion, the recommendation to all chronic pain subjects is daily EVO consumption, preferably raw, as a seasoning for food and a weekly consumption of olives (for example, to be added to salads).

\section{Red meat, white meat and fish}

An unbalanced diet that emphasises the consumption of food of animal origin at the expense of food of plant origin is associated with the development of chronic and degenerative diseases, which, in turn, are related to pain ${ }^{(64)}$.

Components of the Mediterranean diet associated with better cardiovascular health include low consumption of meat and meat products ${ }^{(65)}$.

These foods may produce inflammatory molecules; higher red meat consumption is associated with unfavourable plasma concentrations of inflammatory and glucose metabolic 
biomarkers (such as IL-6) in diabetes-free women, and the substitution of other protein food, such as poultry, is associated with a healthier biomarker profile of inflammatory and glucose metabolism $^{(66)}$.

Moreover, there is the impact of beefsteak thermal processing on lipid oxidation and postprandial inflammation-related responses: Nuora et al. ${ }^{(67)}$ evaluated the effect of the consumption of pan-fried and sous-vide steaks and it was shown that there were no postprandial differences in the plasma IL-6 and CRP levels. TNF- $\alpha$ levels after consuming the pan-fried meal remained at baseline throughout the monitoring period but there was a decrease in TNF- $\alpha$ levels after consuming the sous-vide meal.

Plasma monocyte chemotactic protein-1 (MCP-1) remained unaltered, relative to baseline values, after the pan-fried meal. In contrast, MCP-1 was reduced following the sous-vide meal $^{(67)}$.

In order to obtain an adequate amount of protein if consuming animal products, we recommend consuming white meat twice per week, red/processed meat once per week, and fish four times per week.

Fish should contain larger amounts of $n-3$ PUFA, such as bluefish, mackerel, anchovies, sardines, tuna and swordfish, given the anti-inflammatory properties of these essential fatty acids: for example, the study of Maroon et $a l .{ }^{(68)}$, in which individuals took a supplementation of $n$ - 3 essential fatty acids (EPA and DHA), found in fish oil supplements, demonstrated a reduction of pain ${ }^{(68,69)}$.

Online Supplementary Table S5 summarises the studies showing the relationship between intake of red or white meat or fish and imbalance between antioxidant capacity and oxidative stress and pro/anti-inflammatory markers, conditions present in chronic pain subjects.

In conclusion, excessive consumption of red meat causes an inflammatory state and alternative foods should be taken into consideration such as white meat and fish.

\section{Legumes}

Legumes are a pivotal component of the Mediterranean diet due to their beneficial effect on inflammatory markers.

In a recent cross-over study, subjects with type 2 diabetes were divided into two groups in order to analyse certain inflammatory markers as a result of two different types of 8 -week diet intervention (identical isoenergetic diets, with the exception of two servings of meat replaced by two servings of vegetables). There was a significant decrease in CRP, IL-6 and TNF- $\alpha$ only during the period in which subjects took legumes compared with the period when they took meat, independent of weight change ${ }^{(70)}$. These results were confirmed in a systematic review that involved eight studies and 464 participants, showing that the consumption of legumes (excluding soyabeans) had a significant effect on the reduction of $\mathrm{CRP}^{(71)}$.

Regarding soyabeans, the literature reports that diets rich in soya create an anti-inflammatory effect through activation of the PPAR $\gamma$ receptor with consequent suppression of production of pro-inflammatory cytokines by immune cells ${ }^{(72)}$. Therefore, soya intake may be useful in controlling chronic pain, as reported by
Shir et $a l .{ }^{(73)}$ in which rats were fed a soya or no-soya diet. With regard to studies on human subjects, Arjmandi et al. ${ }^{(74)}$ showed a reduction in pain symptoms in patients with osteoarthritis taking a 3-month supplement of $40 \mathrm{~g} / \mathrm{d}$ of soya proteins, as indicated by a significant increase in serum levels of insulin-like growth factor-1 and a significant decrease in serum levels of glycoprotein 39 (YKL-40) compared with a milk-based protein diet; specifically, the authors underline that major effects were observed in men rather than women, probably for higher levels of oestrogen in women as compared with men, because the effect of soya supplementation is related to its content of isoflavones ${ }^{(74)}$.

The main soya isoflavone is genistein. It has been shown in in vitro studies that genistein binds to oestrogen receptors and activates PPAR- $\boldsymbol{\gamma}$, which has a prominent role in the suppression of inflammatory genes. In cultured chondrocyte cells, put in contact with lipopolysaccharide, genistein reduces IL-1 $\beta$ expression, COX and NO, indicating a clear anti-inflammatory effect $^{(75)}$. The authors underline that there are no pharmaceutical agents that selectively can inhibit COX-2 production without having serious side effects. Therefore, genistein can be an attractive and viable alternative therapy for treatment or prevention of $\mathrm{OA}^{(75)}$.

Finally, legumes are rich in water-insoluble fibre, and this feature makes them suitable for subjects suffering from opioidinduced constipation (OIC).

Online Supplementary Table S6 summarises the studies investigating the relationship between intake of legumes and imbalance between antioxidant capacity and oxidative stress and pro/anti-inflammatory markers, conditions of chronic pain subjects.

In conclusion, it is recommended to consume legumes four times per week, either dried or fresh, and soyabean once per week for their anti-inflammatory activity and their high content of fibre.

\section{Yogurt}

Our body is an ideal habitat for the survival of bacterial strains. These micro-organisms are not always pathogenic; indeed, they often are an important defence and security barrier. The gut is the tract of the human body most colonised and overall resident bacteria form a complex and diverse ecosystem-defined microbiota. The alteration of the intestinal microbiota is a result of various conditions, such as prolonged use of antibiotics, changes in lifestyle, use of drugs, and diseases ${ }^{(76)}$.

Under normal conditions, the intestinal microbiota is made from different bacterial strains belonging mainly to the genera Bacteroides, Eubacterium, Bifidobacterium, Fusobacterium, Peptostreptococcus and to a lesser extent Escherichia coli, Enterobacter and Lactobacillus, which produce a series of molecules able to activate both the innate and acquired immune systems, which may be altered in pathological conditions or during drug treatment ${ }^{(77)}$.

It is therefore necessary that intestinal microbiota be adequately represented, in order to compete with the pathological bacteria that pass through the gastrointestinal tract, and in order to exert beneficial actions in different parts of the human $\operatorname{body}^{(78)}$. 
Opioids, in particular morphine, are the main drugs that determine alteration of the innate and adaptive immunity of the patient, even though the mechanism of action is not fully known ${ }^{(79)}$. Specifically, opioids alter or suppress the function of pro-inflammatory cells (cytokines), through Toll-like receptors (TLR), while opioids in adaptive immunity act on B and $\mathrm{T}$ lymphocytes, respectively, through the hypothalamus-pituitary-adrenal axis, the molecules of histocompatibility class II (MHC II) and through the suppression of IL- $2^{(80)}$. A recent study using animal models showed that chronic use of morphine induces a significant change in the composition of the intestinal microbiota and determines an increase in Gram-positive pathogenic bacteria and a reduction in deconjugating bile strains. Moreover, this study also demonstrated that the Firmiculates:Bacterioidetes ratio, one of the key markers of inflammation in the microbiome, promotes the pro-inflammatory phenotype, demonstrating how the immune status of the host involves the innate immune response ${ }^{(81)}$.

Probiotics are defined by the FAO/WHO as living organisms which bring benefit to the health of the host, when administered in adequate amounts, ${ }^{,(82)}$, while the literature defines prebiotics as a class of food products which constitute the necessary and optimum substrate for the growth and development of probiotics.

Among the prebiotics, inulin (contained in plants of the Lilliaceae family, such as leek, onion, garlic and asparagus, or of the Compositae family such as Jerusalem artichoke, dahlia and chicory), oligofructose and polyphenols have particular importance; they are metabolised by enteric bacteria ${ }^{(83)}$.

Yogurt is the best-known substrate to which to add probiotics. Yogurt may be also be added to prebiotics (for example, fructo-oligosaccharides) that are useful in preventing alterations of the microbiota and to counteract constipation ${ }^{(84)}$, both critical situations induced by opioid therapy.

Yogurt intake is recommended in all pathologies characterised by an inflammatory state ${ }^{(85)}$. The intake of Bifidobacterium animalis subsp. lactis (BB-12) interacts with the peripheral myeloid cells via TLR-2, a receptor capable of recognising certain typical structures of pathogens and microbes, and it is implicated in the defence of the organism, in particular, of innate immunity ${ }^{(86)}$. Subjects who ingested yogurt with BB-12 probiotics had a lower expression of TLR- 2 and thus a decrease in the triggering of the immune response as a result of inflammation. These results demonstrated a potential antiinflammatory effect of BB-12 in healthy adults, and also indicated that the matrix to which the probiotics are added may influence the immunomodulatory properties.

Other authors conducted studies on the activity of probiotics on the immune system. Klein et $a l .{ }^{(87)}$ integrated yogurt with Lactobacillus acidophilus 74-2 and Bifidobacterium animalis subsp. lactis DGCC 420 (B. lactis 420) and demonstrated that the percentage of granulocytes and monocytes with phagocytic activity increased by $92-95 \%$, with a concomitant increase in L. acidophilus and B. lactis concentrations in faeces.

Probiotics (Lactobacillus bulgaricus and Streptococcus thermophilus, as well as other strains that may be added such as Lactobacillus acidophilus 74-2, Bifidobacterium animalis subsp. lactis DGCC 420, Bifidobacterium animalis subsp. lactis), and the protein content in yogurt, have an antiinflammatory and immunomodulatory activity in human subjects, demonstrated by numerous intervention studies ${ }^{(88)}$.

Online Supplementary Table S7 summarises the studies investigating the relationship between intake of yogurt or fermented milk and imbalance between antioxidant capacity and oxidative stress and pro/anti-inflammatory markers, conditions present in chronic pain subjects.

In conclusion, the daily intake of yogurt can prevent the alteration of the microbiota, a consequence of opioid therapy. It is also an excellent way to counteract the inflammatory state that characterises chronic pain patients.

\section{Nuts and seeds and their oils}

The use of seeds (nuts, such as walnuts, hazelnuts, almonds, and pistachios, pumpkin seeds, flax seeds, grapeseed) and oils derived from them for chronic pain treatment has been widely discussed in the literature. In animal models an extract of grape seeds may be useful as a natural treatment option for pain by suppressing the development of peripheral and central sensitisation, probably due to the high content of proanthocyanidins ${ }^{(89,90)}$.

Walnuts are complex food matrices containing different macro- and micronutrients and other components that can influence inflammation and endothelial function. Examples of these components are essential fatty acids, n-3 PUFA, Mg, L-arginine and some antioxidants. Several intervention studies support the anti-inflammatory effect of ALA in human subjects. For example, there was a decrease in serum concentrations of inflammatory markers (CRP and vascular cell adhesion molecule-1 (VCAM-1)) after dietary supplementation with $\mathrm{ALA}^{(91)}$. The increased consumption of ALA from nuts is able to improve anti-inflammatory effects by inhibiting the peripheral production of IL-6, IL- $1 \beta$ and TNF- $\alpha{ }^{(92)}$.

Moreover, walnuts are one of the main sources of $\mathrm{Mg}$ in the diet. Cross-sectional studies have suggested an inverse association between $\mathrm{Mg}$ intake and the concentrations of $\mathrm{CRP}^{(93)}$. Some lines of experimental evidence have also suggested that $\mathrm{Mg}$ intake may have beneficial effects on endothelial function ${ }^{(94)}$, probably mediated by the effects of this mineral on systemic inflammation. As regards arginine, a conditionally essential amino acid contained in high amounts in walnuts $(3.62 \mathrm{~g}$ in $100 \mathrm{~g}$ ), it could have a positive effect on endothelium-dependent vasodilatation $^{(95)}$; however, endothelium-independent vasodilation and levels of intercellular adhesion molecule-1, CRP, homocysteine and oxidation biomarkers were similar after each diet (a Mediterranean diet and a diet in which walnuts replaced about $32 \%$ of the energy from monounsaturated fat ${ }^{(95)}$. A cross-sectional study evaluated the association between the intake of arginine and CRP, demonstrating that individuals with higher intakes of arginine had $30 \%$ less probability of having a CRP of more than $3.0 \mathrm{mg} / \mathrm{l}$. All studies led to the conclusion that the consumption of foods rich in arginine, such as nuts, can reduce the risk of diseases characterised by the presence of inflammation ${ }^{(96)}$.

Pistachio is another seed with significant anti-inflammatory activity. It is particularly rich in $\gamma$-tocopherol, vitamin $\mathrm{K}$, phytosterols, carotenoids, some minerals ( $\mathrm{Cu}, \mathrm{Fe}$ and $\mathrm{Mg}$ ) and 
$\mathrm{B}$ vitamins ${ }^{(97)}$. A diet rich in pistachios (pistachio was added for 4 weeks by replacing the monounsaturated fat content constituting about $20 \%$ of daily energy intake) significantly improves endothelium-dependent vasodilatation $(+30 \%)$, contributes to a decrease in serum IL-6, total oxidant status, lipid hydroperoxide, and malondialdehyde, and leads to an increase in superoxide dismutase, with a significant change in TNF- $\alpha$ levels and $\mathrm{CRP}^{(98)}$.

Flax seeds, rich in ALA, are also known for their antiinflammatory effect: Faintuch et al. ${ }^{(99)}$ showed a decrease in CRP values, serum amyloid A, leucocytes and fibronectin in a group of obese patients, supplemented with $30 \mathrm{~g} / \mathrm{d}$ of flax flour.

Pumpkin seeds have several beneficial effects on health, including antioxidant and anti-inflammatory properties. They have a high content of vitamin $\mathrm{E}$ (tocopherol) ${ }^{(100)}$. Chang ${ }^{(101)}$ found that the administration of pumpkin extract can significantly increase the blood and hepatic activity of superoxide dismutase and glutathione peroxidase in mice, as well as the concentration of malonaldehyde.

Pumpkin seeds are considered a good source of antiinflammatory substances, which can help in many diseases, such as arthritis. Pumpkin seed oil can significantly inhibit arthritis in mice, with an action similar to indomethacin ${ }^{(102)}$

Online Supplementary Table S8 summarises the studies about the relationship between intake of oilseeds and imbalance between antioxidant capacity and oxidative stress and pro/anti-inflammatory markers, conditions present in chronic pain subjects.

In conclusion, the intake of $30 \mathrm{~g} / \mathrm{d}$ of oilseeds (particularly walnuts and pistachios) can be a suitable nutritional option to counterbalance the pro-inflammatory activity in chronic pain patients.

\section{Spices}

It is clear that the Mediterranean diet has an important antiinflammatory role, probably affecting the arachidonic acid cascade, the expression of some proinflammatory genes, and the activity of immune cells ${ }^{(103)}$. The adoption of this dietary pattern could counter the effects of several inflammatory markers, decreasing, for example, the secretion of circulating and cellular biomarkers involved in the atherosclerotic process ${ }^{(104)}$.

Daily consumption of spices is often recommended because they are useful for flavouring dishes without using excessive amounts of salt, but spices have many other positive health properties. The extracts of plants belonging to the Zingiberaceae family (for example, turmeric, ginger, Javanese and galangal ginger) are powerful ipoalgesic agents, useful in chronic pain treatment ${ }^{(105)}$. Specifically, curcumin (obtained from Curcuma longa) attenuates hyperalgesia induced by opioids, one of the main chronic pain treatments, possibly by inhibiting CaMKII $\alpha(\mathrm{Ca} /$ calmodulin-dependent protein kinase type II alpha chain) and its downstream signalling ${ }^{(106)}$. In addition, curcumin has antinociceptive and anti-inflammatory effects $^{(107)}$.

Treatments with herbal preparations (including Zingiber officinale) are useful in reducing chronic joint pain ${ }^{(108)}$. Gingerols and shogaols, found in Zingiber officinale, have an analgesic effect as they are agonists of the transient receptor potential (TRP) cation channel subfamily V1 (TRPV1), showing inhibitory activity on the metabolism of arachidonic acid through COX2 (PG and thromboxanes) ${ }^{(109,110)}$.

In addition, gingerols also exert analgesic effects through the activation of vanilloid receptor subtype-1 (VR1); the potency of gingerols increases with increasing size of the side chain and with the overall hydrophobicity in the series ${ }^{(111)}$. Finally, a particularly volatile compound present in many spices (such as oregano, cinnamon, rosemary, thyme and black pepper), named $\beta$-caryophyllene, is a selective agonist of the peripheral cannabinoid receptor type 2 (CB2), involved in modulating inflammation, especially in neuropathic pain, by reducing pain and neuro-inflammation in animal models ${ }^{(112)}$.

Online Supplementary Table S9 summarises studies investigating the relationship between spice intake and imbalance between antioxidant capacity and oxidative stress and pro/antiinflammatory markers, conditions of chronic pain subjects.

In conclusion, the daily use of spices, especially turmeric and ginger, could have a significant positive activity on chronic pain control due to their antinociceptive and anti-inflammatory actions.

\section{Eggs}

Eggs contain particularly beneficial substances, such as fatsoluble and B vitamins, minerals, choline and carotenoids, highquality proteins, and bioactive components with both pro- and anti-inflammatory roles that contribute to fighting inflammation in human populations.

Phospholipids (for example, phosphatidylcholine, phosphatidylethanolamine, lysophosphatidylcholine, phosphatidylinositol and sphingomyelin), mostly found in the yolk, are an example of this dual role: although the evidence suggests that phosphatidylcholine has anti-inflammatory effects ${ }^{(113,114)}$. Through the role of TNF- $\alpha$, phospholipids are also involved in inflammatory and atherosclerosis processes through the formation of trimethylamine$\mathrm{N}$-oxide, which promotes the formation of atherosclerotic plaques $^{(115)}$.

For this reason, in addition to the known higher cholesterol content, it is recommended to limit egg intake to twice per week. Eggs also contain lutein and zeaxanthin (belonging to the family of carotenoids) with antioxidant and anti-inflammatory properties, whose bioavailability is greater than in vegetable foods. Notably, normal-weight individuals have greater proinflammatory responses to egg intake than overweight individuals with the metabolic syndrome, or type 2 diabetes ${ }^{(112)}$. A recent study highlighted the ability of eggs (one egg per d) to decrease TNF- $\alpha$ in populations with a low degree of chronic inflammation $^{(116)}$.

Online Supplementary Table S10 summarises studies about the relationship between intake of eggs and imbalance between antioxidant capacity and oxidative stress and pro/anti-inflammatory markers, conditions of chronic pain subjects.

\section{Cheeses}

It is known that dairy products (milk, yogurt and cheese) exert important functions in the human body thanks to the content of 
high-quality proteins, Ca and vitamins, in particular vitamin D, and for this reason they should be taken daily. Cheeses are divided into fresh and mature: the first include ricotta, mozzarella, first salt, and cottage cheese. Among the latter, examples are Parmesan, fontina, provolone and scamorza. Experimental and epidemiological studies have shown that regular intake of dairy products has inhibitory effects against the development of some chronic degenerative diseases, characterised by low levels of inflammation, such as the metabolic syndrome $e^{(117)}$.

Moreover, some cheeses contain whey protein, quickly absorbed by the human body, with antioxidant properties ${ }^{(118)}$. Whey protein may exert its effect by enhancing glutathione concentration $^{(118)}$

Schmidt et al. ${ }^{(119)}$ compared the effect of a high-fat dairy meal, a high-fat non-dairy meal supplemented with milk and a high-fat non-dairy control meal on postprandial inflammatory and metabolic responses in healthy men: they suggested that full-fat milk and dairy products have no significant impact on the inflammatory response to a high-fat meal ${ }^{(119)}$.

Demmer et al. ${ }^{(120)}$ performed a randomised controlled crossover trial and compared the intake of saturated fat in the form of cheese compared with plant sources of saturated fat; the results of this study demonstrated that postprandial CRP was significantly lower in response to the cheese compared with the vegan test meal $^{(120)}$.

The 6-week cross-over study by Dugan et al. ${ }^{(121)}$, which compared inflammatory responses (IL-6, IL-1 $\beta$, TNF- $\alpha$ and MCP-1) as a result of diet with low-fat dairy (10 oz (283 g) $1 \%$ milk, $6 \mathrm{oz}(170 \mathrm{~g})$ non-fat yogurt, $4 \mathrm{oz}(113 \mathrm{~g}) 2 \%$ cheese) or with low-fat non-dairy intake (carbohydrate-based control: 1.5 oz (43 g) granola bar and 12 oz (340 g) 100\% juice), demonstrated in patients with the metabolic syndrome that three dairy product servings per d of low-fat dairy food improved systemic inflammation $^{(121)}$

The same positive results have been demonstrated by Bordoni et al. ${ }^{(122)}$ who carried out a systematic review of fiftytwo clinical trials investigating inflammatory markers in relation to the consumption of dairy products. However, in this review there are important limitations; in particular no distinction is made between cheeses with a lower content of saturated fat and cheeses with a high content of saturated fat and cholesterol; in fact, it is well known that excessive intake of saturated fat and cholesterol can cause increased levels of inflammation. Recently, Rocha et al. ${ }^{(123)}$ provided a new perspective on the potential mechanism by which SFA could modulate TLR4induced inflammatory responses. However, now even this topic is heavily debated in the literature because the results do not all agree. Van Meji \& Mensink ${ }^{(124)}$ carried out a comparative study on the inflammation response in which thirty-five overweight subjects consumed, in a random order, low-fat dairy products (500 ml low-fat milk and $150 \mathrm{~g}$ low-fat yogurt) or carbohydraterich control products ( $600 \mathrm{ml}$ fruit juice and three fruit biscuits) daily for 8 weeks. The results of this study indicated that in overweight subjects, low-fat dairy product consumption, compared with carbohydrate-rich product consumption, may modulate TNF- $\alpha$ signalling by increasing soluble TNF receptor2 , but that it does not affect other markers of low-grade systemic inflammation and endothelial function in overweight subjects $^{(124)}$.

Online Supplementary Table 11 summarises studies that investigate the relationship between intake of cheeses and imbalance between antioxidant capacity and oxidative stress and pro/anti-inflammatory markers, all conditions present in chronic pain subjects.

In conclusion, the intake of cheeses, in particular with a high content of whey protein, is recommended at least twice per week.

\section{Red wine}

The consumption of moderate doses of wine (one glass of $125 \mathrm{ml} / \mathrm{d}$ for women and two glasses for men) is useful in the prevention of many inflammatory diseases, probably by activating sirtuin-1 (SIRT1) ${ }^{(125,126)}$.

Red wine is rich in numerous active molecules against inflammation and oxidative stress (in particular flavonoids, such as quercetin and myricetin, catechin and epicatechin, proanthocyanidins, anthocyanidins and the stilbene resveratrol). These molecules determine an increased expression of nicotinamide adenine dinucleotide (NAD)-dependent deacetylase SIRT1, a protein capable of deacetyl nuclear and cytoplasmic proteins controlling critical cellular processes, such as apoptosis and metabolism. SIRT1 regulates the production of insulin and glucose, lipids and cell survival ${ }^{(127)}$.

Flavonoids have a significant positive effect on immune system functions and on inflammatory cells, as demonstrated in numerous in vitro and animal model studies ${ }^{(128,129)}$. Flavonoids are able to inhibit the expression of isoforms of NO synthase, COX and lipoxygenase, which are responsible for the production of a large amount of NO, prostanoids, leukotrienes, and other mediators of the inflammation process such as cytokines, chemokines and adhesion molecules ${ }^{(130)}$. The flavonoids also inhibit phosphodiesterase involved in cell activation. Many antiinflammatory effects of the flavonoids affect the biosynthesis of cytokines that mediate adhesion of circulating leucocytes to sites of injury. Some flavonoids are potent inhibitors of the production of PG, a group of powerful pro-inflammatory signalling molecules ${ }^{(131)}$.

As regards resveratrol, recent studies have shown that it modulates neuronal excitability in the nervous system, both central and peripheral channels through the TRP ion channels and voltage-dependent channels ${ }^{(132-136)}$.

For example, TRP ankyrin 1 (TRPA1) modulates the mechanical transduction in primary sensory neurons ${ }^{(137)}$, and it has been shown that resveratrol is a potent inhibitor of TRPV1 in vitro and in vivo ${ }^{(136)}$, suggesting that resveratrol attenuates the generator potential via the mechanical transduction process. In addition, resveratrol modulates the channels of $\mathrm{Na}$ and $\mathrm{K}$ in the dorsal root ganglia neurons that are associated with the generation of action potentials $^{(132,133)}$. On the contrary, in the hippocampus, resveratrol significantly suppresses glutamateinduced currents in CA1 pyramidal postsynaptic neurons ${ }^{(138)}$ that contribute to excitatory synaptic transmission. In addition, literature data show that resveratrol decreases the duration of the action potential and L-type $\mathrm{Ca}^{2+}$ currents in excitable tissues $^{(134)}$. Together, these results suggest that systemic 
administration of resveratrol may suppress sensory transmission, including nociception, in both the central and peripheral nervous system, as demonstrated in a recent animal model study, in which the acute intravenous administration of resveratrol suppressed trigeminal nociceptive transmission ${ }^{(139)}$.

Online Supplementary Table S12 summarises the studies about the relationship between red wine intake and imbalance between antioxidant capacity and oxidative stress and pro/antiinflammatory markers, present in chronic pain subjects.

In conclusion, the numerous molecules active against inflammation and oxidation of red wine determine increased expression levels of SIRT1. Resveratrol modulates neuronal excitability. It is recommended to consume one $125 \mathrm{ml}$ glass $/ \mathrm{d}$ for women and two glasses for men to control pain in chronic pain patients without continuous opioid and/or benzodiazepine drug treatments; a greater amount should be avoided because of the risk of addiction/abuse.

\section{Alcohol consumption and opioids}

The association between alcohol and opioid analgesics may result in 'dose dumping'. This is defined as the unintended quick release (in a short period of time) of the total amount (or a significant fraction) of the drug in a dosage form with modified release.

Alcohol is related to dose-dumping in all long-acting specific opioid formulations (LAO), and it significantly increases their side effects ${ }^{(140)}$. Therefore, it has been recommended that patients not drink alcohol during treatment, because they may have the rapid release and absorption of a potential fatal dose of opioids ${ }^{\text {(141) }}$.

The mechanism by which alcohol alters the pharmacokinetic properties of LAO are little known. Several studies have shown that the concomitant use of alcohol increases the maximum plasma concentration $\left(\mathrm{C}_{\max }\right)$ of some opioids and decreases the time to $\mathrm{C}_{\max }\left(\mathrm{T}_{\max }\right)$, despite no evidence of dose dumping $^{(142-144)}$. Specifically, Fiske et al $^{(142)}$ demonstrated that increased systemic exposure to oxymorphone was greatest in the presence of excessive levels of ethanol ( $40 \%$ ), which models serious ethanol abuse, but its clinical importance is not known.

These observations underscore the importance of educating patients not to consume alcoholic beverages while taking LAO therapies. Fatal poisonings involving pharmacological opiates are often associated with the use of alcohol and are probably due to a combination of effects on the central nervous system and of the respiratory $\operatorname{tract}^{(145,146)}$.

Ali et $a .^{(147)}$ showed that opioids have a significantly decreased ventilatory response to hypercapnia when administered together with ethanol. About $12 \%$ of patients under chronic opioid treatment consume ethanol ${ }^{(148)}$, and therefore physicians must take into consideration the possible development of adverse events ${ }^{(149)}$.

In conclusion, given the prevalence of concomitant use of opioids and ethanol and the potential risks to health (respiratory depression and sedation) associated with simultaneous administration $^{(150)}$, it is important to implement information on safety, pharmacokinetics and pharmacodynamics following concurrent administration of alcohol and opioids.

\section{Homemade sweets}

The consumption of sweets is placed at the top of the pyramid, signifying that their intake should be occasional (maximum once per week). As described in the chapter on cereal consumption, the intake of high-glycaemic index foods (and sweets are foods with a high glycaemic index) can contribute to greater oxidative stress and create a state of low-grade chronic inflammation $^{(35)}$.

The intake of a Western-style diet (with high amounts of simple sugars and sweets) causes an increase in inflammatory markers ${ }^{(151)}$, such as CRP, IL-6, E-selectin, soluble intercellular adhesion molecule-1 (sICAM-1) and soluble vascular cell adhesion molecule-1 (sVCAM-1), after adjustment for all confounding factors ${ }^{(152,153)}$.

Nevertheless, we should not underestimate the positive effect of dark chocolate (minimum $70 \%$ of cocoa solids) that is able to reduce NO production and then oxidative stress thanks to its flavonoid content ${ }^{(154)}$. Regular consumption of dark chocolate determines the reduction in inflammation, evaluated by $\mathrm{CRP}^{(155)}$

Online Supplementary Table S13 summarises studies investigating the relationship between intake of sweets and imbalance between antioxidant capacity and oxidative stress and pro/anti-inflammatory markers, conditions present in chronic pain subjects.

In conclusion, it is right to enjoy the satisfaction of consuming a sweet, but homemade preparations are preferred, based on wholemeal flour with a lower glycaemic index than a refined one, and dark chocolate ( $70 \%$ cocoa).

\section{Dietary supplements}

On top of the food pyramid for the dietary management of chronic pain there is a pennant, to remind us that chronic pain subjects require special dietary supplements: vitamin $D$, vitamin $\mathrm{B}_{12}$, micronutrients ( $\mathrm{Zn}$ and $\mathrm{Se}$ ), fibre and $n-3$ fatty acids.

Vitamin D. Vitamin D is classified as a fat-soluble vitamin and it is activated in the skin by exposure to sunlight, while only $20 \%$ is taken with food (especially through food of animal origin such as eggs, salmon, herring and liver).

If the diet is not sufficient to satisfy the Recommended Daily Allowance (RDA) of vitamin D, its supplementation is necessary because hypovitaminosis $\mathrm{D}$ is accompanied by numerous diseases, namely osteoporosis and musculoskeletal problems, but the literature also suggests an association between vitamin D deficiency and chronic pain ${ }^{(156)}$. Vitamin D deficiency correlates with a greater likelihood of developing chronic widespread pain ${ }^{(157)}$. In accordance with these results, Costan et $a{ }^{(158)}$ demonstrated that supplementation with vitamin D (daily bread fortified with $125 \mu \mathrm{g}$ vitamin $\mathrm{D}_{3}$ ) in patients with osteoporosis and residing in a nursing home not only improves bone health and quality of life, but also locomotion, daily activities and pain.

The literature data have explained this link between vitamin $\mathrm{D}$ and chronic pain, demonstrating that low levels of vitamin D are associated with increased central hypersensitivity, such as increased sensitivity to mechanical pain and severity of 
somatic symptoms in chronic pain patients ${ }^{(159)}$. It also points out that vitamin D plays a crucial role in diseases related to the immune system and in autoimmune disease, because the receptors for the vitamin are not only present in cells related to Ca homeostasis, but also in cell lines involved in immune regulation (for example, dendritic cells) ${ }^{(160)}$.

Moreover, treatment with vitamin D improves the quality of sleep, mood, and the level of pain. For example, Shipton \& Shipton ${ }^{(161)}$ and Straube et al. ${ }^{(162)}$ evaluated the effect of supplementation of vitamin D; however, in both studies it could not be stated conclusively that vitamin D deficiency was directly linked to the aetiology or maintenance of chronic pain states.

Online Suplementary Table S14 summarises the studies about the relationship between intake or supplementation of vitamin $\mathrm{D}$ and imbalance between antioxidant capacity and oxidative stress and pro/anti-inflammatory markers, conditions present in chronic pain subjects.

In conclusion, in chronic pain patients, the assessment of blood vitamin $\mathrm{D}$ is recommended.

Vitamin $B_{12}$. Vitamin $B_{12}$ (cobalamin) is a water-soluble vitamin and is found in foods of animal origin (meat, eggs, fish), although some micro-organisms and certain algae are able to produce it. In many studies, the anti-nociceptive effects of the vitamin have been highlighted $^{(151,152)}$. In a recent study on mice, vitamin $\mathrm{B}_{12}$ was co-administered with morphine and the results showed a reduction in the development of morphine tolerance, probably through the indirect inhibition of NMDA receptors, and, consequently inhibition of NO synthesis ${ }^{(163)}$. Other similar experiments on animal models have highlighted the anti-inflammatory effects of cobalamin supplementation in enhancing its potential use for the treatment of acute and chronic neuropathic pain ${ }^{(164)}$.

Recently, human studies have shown that the intramuscular injection of vitamin $\mathrm{B}_{12}$ is significantly important for the treatment of localised pain in the spine ${ }^{(165)}$. In particular, Chiu et $a l^{(165)}$ demonstrated that intramuscular methylcobalamin is both an effective and safe method of treatment for patients with non-specific low back pain.

Online Supplementary Table S15 summarises the studies investigating the relationship between intake or supplementation of vitamin $\mathrm{B}_{12}$ and imbalance between antioxidant capacity and oxidative stress and pro/anti-inflammatory markers, conditions present in subjects with chronic pain.

In conclusion, if the diet is not sufficient to satisfy the Recommended Daily Allowance (RDA) of vitamin $\mathrm{B}_{12}$, in chronic pain subjects, it would be suitable to recommend the evaluation of blood vitamin $\mathrm{B}_{12}$ and a specific supplementation.

n-3 PUFA. Linolenic acid and its metabolites ( $n-3$ PUFA) are well known for their anti-inflammatory properties, as well as analgesic and anti-nociceptive activities: Freitas et al. ${ }^{(166)}$ evaluated a supplementation of fish oil in mice via modulation of circulating lymphocytes, besides GPR40/FFAR1 expression at the spinal level ${ }^{(166,167)}$

The main derivatives are $n-3$ EPA $(20: 5)$ and DHA (22:6) and it is interesting to remember how the enzyme $\Delta-6$ desaturase, the key enzyme for the transformation from linolenic acid to EPA and DHA, its active metabolites, may be deficient in some situations, for example, ageing. Thus, it appears to be advantageous to administer EPA and DHA and not the precursor linolenic acid.

$n$-3 Fatty acids are found in fatty fish (salmon, tuna, etc.) and some plant sources, such as flaxseed and algae. In general, PUFA are able to activate the hypothalamic GPR40 protein, which in turn plays an important role in chronic pain control ${ }^{(69)}$. Some studies have shown that the regular consumption of PUFA (as supplementation) is equivalent to some drugs for the treatment of joint pain and constitutes an available alternative to NSAID ${ }^{(68)}$. The effectiveness of $n-3$ essential fatty acids in rheumatoid arthritis and some cases of osteoarthritis has been demonstrated in the study of Maroon et al. ${ }^{(68)}$; the conversion of EPA into anti-inflammatory PG of the PGE3 series is by the same COX enzyme used by arachidonic acid to convert to the proinflammatory PG PGE2 series ${ }^{(68)}$

Moreover, an animal model study suggested a role of $n-3$ supplementation as an adjunct to opioids in pain therapy, showing that they might contribute to the reduction of the occurrence of morphine side-effects ${ }^{(168)}$.

However, a review by Boe \& Vangsness ${ }^{(169)}$ concluded that despite the overwhelming popularity of fish oil supplements and the assumption of benefit for patients with chronic pain in arthritis, there is insufficient clinical evidence at this moment to justify the use of fish oil in the treatment or prevention of osteoarthritis; for this reason there remains a significant need for trials to evaluate the efficacy and safety of $n-3$ fatty acids in a standardised form ${ }^{(169)}$.

Online Supplementary Table S16 summarises studies regarding the relationship between intake or supplementation of $n$-3 PUFA and imbalance between antioxidant capacity and oxidative stress and pro/anti-inflammatory markers, conditions in chronic pain subjects.

In conclusion, if chronic pain subjects are unable to consume four portions of fish/week, it is helpful to take a daily dietary supplementation of $1800 \mathrm{mg}$ of EPA and $1200 \mathrm{mg}$ of DHA.

Fibre. According to the Guidelines for Italian healthy eating, fibre consumption is optimal in the order of $30 \mathrm{~g} / \mathrm{d}^{(20)}$. Normally, proper nutrition involves the introduction of fruit and vegetables as well as whole grains that are naturally rich in fibre and that meet the daily requirement. Fibres are classified into two major groups: soluble and insoluble ${ }^{(20)}$. Insoluble fibre (cellulose, lignin and hemicellulose) resists the action of digestive enzymes and is mixed with faeces; it increases the volume of stool, making it softer and homogeneous. Insoluble fibre is present mainly in whole grains. The water-soluble fibres (pectins, gums, mucilages, guar gum, oligosaccharides) absorb water, swell, and become a gelatinous mass. Soluble fibre is present in fruits and vegetables.

In the correct diet, it is necessary to associate the two types of fibre, in order to alleviate constipation ${ }^{(170,171)}$.

While increasing the consumption of fibre, it is also important to increase and ensure an adequate intake of fluids, particularly in the summer, when fluid loss is higher.

Dehydration is a potential cause of the increased risk of constipation, which could also be solved by maintaining a 
proper distribution of meals during the day, in order to properly activate the gastro-ileocaecal reflection, favouring the progression of the food to the rectum.

Online Supplementary Table S17 summarises the studies about the relationship between intake of supplementation of fibre and constipation, conditions present in chronic pain subjects, in particular in patients with opioid-related adverse drug events.

In conclusion, a diet rich in fibre $(30 \mathrm{~g} / \mathrm{d}$, in a ratio of 3:1 between insoluble and soluble fibre with an adequate intake of water) can be helpful in reducing the glycaemic response of the diet and in preventing and solving problems related to the consumption of drugs used to combat chronic pain, such as OIC.

\section{Role of dietary fibre in opioid-induced constipation}

The most current diagnostic criteria of constipation have been developed during the Rome III Consensus Conference ${ }^{(172)}$ :

(1) At least two or more of the following characteristics in at least $25 \%$ of the discharges: effort in defecation of hard stools; sensation of incomplete evacuation; feeling of occlusion; less than three defecations per week; need for manual manoeuvre to evacuate.

(2) Rare evacuations without resorting to laxatives.

(3) Exclusion from the diagnosis of irritable bowel syndrome.

Presence of other symptoms, such as bloating or abdominal distension, may be present, but they are not the symptomatic elements. The pathological mechanism, which causes the OIC, is due to the effect of these drugs on peripheral $\mu$-receptors in the gut wall ${ }^{(173)}$. The $\mu$-opioid receptors are present in the neurons of the myenteric plexus and submucosal and immune cells of the lamina propria $^{(174)}$. The activation of $\mu$-opioid receptor inhibits neuronal excitatory and inhibitory pathways in the enteric nervous system, which coordinates motility.

The inhibition of excitatory neuronal pathways decreases peristaltic contractions; the blockade of inhibitory neuronal processes increases the muscular activity of the gastrointestinal tract and elevates the resting muscle tone with the consequence of inducing spasm. These mechanisms lead to a delay in gastric emptying and slow intestinal transit ${ }^{(175)}$.

The opioid drugs in cancer patients increase the use of treatment for constipation, with a predominance of monotherapy ${ }^{(176)}$. Patients using opioids, suffering from OIC, incur a greater number of adverse effects, which result in increased use of medical care, thereby raising the cost of health care. Patients with opioid-related adverse drug events have a great risk for hospitalisation, ranging from $10 \cdot 3$ to $55 \%$.

Estimates of OIC have been found to vary widely, with investigations identifying rates of OIC among opioid users ranging from 15 to $90 \%{ }^{(18,177-179)}$, resulting in an increase in care costs from $7 \cdot 4$ to $47 \%{ }^{(180)}$.

Improving the management of constipation can lead to an optimisation of drug therapy and prevents the interruption of opioid drugs already in use. This interruption would lead to deterioration in the quality of life, which in turn would lead the patient to new access to medical care, with recovery therapy with multiple drugs and associated increased costs ${ }^{(181)}$.
About $10 \%$ of emergency room visits have a diagnosis of constipation. Furthermore, constipation was reported to be one of four factors that significantly and independently predict hospitalisation in hospice care ${ }^{(182)}$. Several studies in patients with advanced cancer receiving hospice care in fact showed that the prevalence of constipation is between 23 and $84 \%{ }^{(183-189)}$. In addition, a series of studies conducted in a large hospice in Florida evaluated OIC, demonstrating that it occurs in $40-64 \%$ of hospitalised cancer patients. However, the number was found to be lower when the data were obtained from a screening of staff (40\%) and higher when the researchers interviewed patients about their symptoms $(63-64 \%)^{(189-191)}$.

Moreover, it is important to note that possible associations have been hypothesised between the impairment of intestinal integrity and musculoskeletal chronic pain, like fibromyalgia and chronic myofascial pain, emphasising the synthesis and release of proinflammatory cytokines in these clinical situations ${ }^{(192)}$

In conclusion, counteracting constipation is an important point in the management of patients with opioid-related adverse drug events, as various studies have shown that the presence of constipation is significantly negatively correlated to the overall quality of life $\mathrm{e}^{(193-196)}$.

Multidisciplinary patient management, including analysis of life-style, should be performed at the beginning of opioid therapy and continue for the duration of the treatment; typical measures should include consumption of dietary fibre, fluid and increased physical activity ${ }^{(197)}$.

In ambulatory cancer patients with drug-induced constipation, an increase in fibre consumption should be recommended up to $30-35 \mathrm{~g} / \mathrm{d}^{(198)}$, according to specific protocols ${ }^{(199-200)}$. Animal model studies confirm that fibre can be a preventive factor for OIC. Moreover, the presence of SCFA products from the microbiota improve intestinal transit, promoting colon motility ${ }^{(201)}$. The use of prebiotics could further help, improving immunity in the intestine, increasing IgA and acting on oxidative stress, positively affecting intestinal peristalsis ${ }^{(202)}$.

OIC improvement may also occur thanks to nonpharmacological management. Cancer patients should be encouraged to eat more high-fibre foods, such as fruits (plums, peaches and apples), vegetables (squash, broccoli, carrots and celery) and whole grains, and to increase fluid intake ${ }^{(203)}$.

Online Supplementary Table S18 summarises the studies about the relationship between intake of supplementation of fibre and constipation, conditions present in patients with opioid-related adverse drug events.

In conclusion, a targeted diet, rich in fibre $(35 \mathrm{~g} / \mathrm{d}$, in a ratio of 3:1 between insoluble and soluble fibre with an adequate intake of water) and with five meals daily, can be helpful in preventing and solving problems related to the assumption of drugs used to combat chronic pain, such as OIC.

Micronutrients: zinc and selenium. Zn, the second most abundant trace element in the human body (after Fe) ${ }^{(204)}$, plays mainly antioxidant and anti-inflammatory $\operatorname{roles}^{(205)}$; as a cofactor of $\mathrm{Cu}-\mathrm{Zn}$ superoxide dismutase, it is important for antioxidant defence ${ }^{(206)}$ and $\mathrm{Zn}$ depletion increases the inflammatory status, impairs immune system functioning, 
antioxidant defence, and affects DNA structure ${ }^{(207-209)}$. Moreover, in animals, $\mathrm{Zn}$ formulations determine, at non-toxic systemic or local doses, indubitable analgesic effects in different models of pain: acute visceral, mechanical and thermal pain, under regular, inflammatory and neuropathic conditions ${ }^{(210-213)}$.

Se is also an essential trace mineral important to human health $^{(214,215)}$. This mineral constitutes a key component of various selenoproteins involved in enzymic activities and particularly in redox homeostasis and in thyroid hormone metabolism ${ }^{(216,217)}$

Moreover, optimal Se intake can mitigate dysfunctional inflammatory responses, in part, through the regulation of eicosanoid metabolism ${ }^{(218)}$. A poor Se status has been associated with an increased risk of several chronic diseases ${ }^{(214)}$ and cancer ${ }^{(219)}$.

In humans, an inadequate intake of both $\mathrm{Zn}$ and Se and their low intracellular stores are correlated with pain in patients with chronic myofascial pain ${ }^{(220)}$.

Finally, a recent review by Ciubotariu et al. ${ }^{(221)}$ showed that both human and animal studies revealed decreased serum $\mathrm{Zn}$ under opioid-administration conditions, attributed mainly to increased urinary elimination (humans) or redistribution (animals).

For all these reasons, Ciubotariu et $a l^{(221)}$ concluded that $\mathrm{Zn}$ dietary supplementation in patients treated with opioids for cancer-related chronic pain should be considered, due to the high incidence of $\mathrm{Zn}$ deficiency, also well-documented in opioid consumers.

Online Supplementary Table S19 summarises studies regarding the relationship between intake or supplementation of $\mathrm{Zn}$ and Se and imbalance between antioxidant capacity and oxidative stress and pro/anti-inflammatory markers, conditions in chronic pain subjects.

In conclusion, the assessment of the intake of $\mathrm{Zn}$ and Se by dietary diary, possibly associated with $\mathrm{Zn}$ and plasma Se evaluation, are important assessments to be made in a chronic pain patient, particularly in patients who undergo opioid treatment, in order to consider dietary supplementation with $\mathrm{Zn}$ and Se.

\section{Conclusion and limitations}

A specific diet can provide helpful support in patients suffering from chronic pain. Moreover, a targeted diet can also help to solve problems related to the consumption of drugs used to combat chronic pain, such as constipation. Chronic pain is strictly associated with inflammation and oxidative stress, though other factors can also contribute significantly to chronic pain, such as psychosocial factors, biomechanical factors, other causes of neural pain processing, etc. For this reason we have performed a review in which we have considered scientific papers basing on the assumption that lower inflammation and oxidative stress are related to lower pain.

However, it is important to note that the causal relationship between the higher inflammatory biomarkers found in chronic pain patients is largely unknown, because various vicious circles have been involved concerning, for example, stress. The stress of being in pain chronically may increase inflammatory markers themselves, so it is possible that chronic pain causes inflammation, not the other way around. Dysfunctional bidirectional pathways between stress, inflammation, the brain and the immune, endocrine and neurotransmitter systems have been extensively described and implicated in pain ${ }^{(200)}$.

Thus, the nutrition pyramid described in our review is hypothetical, even in the light of several limitations of the present review. The main limitation is the fact that to date there are no randomised controlled trials in the literature clearly showing that improved nutrition, via a lowering of general inflammation, improves chronic pain. Further, to build the pyramid, we could only make a narrative review of the literature, not a meta-analysis.

A further limitation concerns in particular the section dedicated to supplementation; as a matter of fact the antiinflammatory activity demonstrated by in vitro and in vivo studies for giving an isolated nutrient is not equivalent to getting the same nutrients in real whole foods. There are numerous examples in the literature where this presumption does not hold up.

In conclusion, even if this nutritional pyramid is hypothetical, we hope that it can serve the valuable purpose of helping researchers focus on the often-ignored possible connections between nutrition and chronic pain. Further investigation is needed in the future and, specifically, more randomised clinical trials should be conducted that directly study nutrition and chronic pain, in order to understand the specific mechanisms that interconnect inflammation, chronic pain and nutrition.

\section{Acknowledgements}

The authors declare no commercial or financial conflict of interests.

\section{Supplementary material}

To view supplementary material for this article, please visit https://doi.org/10.1017/S0954422417000270

\section{References}

1. Tick H (2015) Nutrition and pain. Phys Med Rehabil Clin N Am 26, 309-320.

2. Zhang JM \& An J (2007) Cytokines, inflammation, and pain. Int Anesthesiol Clin 45, 27-37.

3. Hatakeyama N \& Matsuda N (2014) Alert cell strategy: mechanisms of inflammatory response and organ protection. Curr Pharm Des 20, 5766-5778.

4. Swieboda P, Filip R, Prystupa A, et al. (2013) Assessment of pain: types, mechanism and treatment. Ann Agric Environ Med 1, 2-7.

5. Sokol CL \& Luster AD (2015) The chemokine system in innate immunity. Cold Spring Harb Perspect Biol 7, a016303.

6. Mittal M, Siddiqui MR, Tran K, et al. (2014) Reactive oxygen species in inflammation and tissue injury. Antioxid Redox Signal 20, 1126-1167.

7. Pan MH, Lai CS, Ho CT, et al. (2010) Anti-inflammatory activity of natural dietary flavonoids. Food Funct 1, 15-31.

8. Libby P (2006) Inflammation and cardiovascular disease mechanisms. Am J Clin Nutr 83, 456S-460S.

9. Brouwers H, von Hegedus J, Toes R, et al. (2015) Lipid mediators of inflammation in rheumatoid arthritis and osteoarthritis. Best Pract Res Clin Rheumatol 29, 741-755. 
10. Conaghan PG, Kloppenburg M, Schett G, et al. (2014) Osteoarthritis research priorities: a report from a EULAR ad hoc expert committee. Ann Rheum Dis 73, 1442-1445.

11. Kulkarni K, Karssiens T, Kumar V, et al. (2016) Obesity and osteoarthritis. Maturitas 89, 22-28.

12. Aguilar-Valles A, Inoue W, Rummel C, et al. (2015) Obesity, adipokines and neuroinflammation. Neuropharmacology 96, 124-134.

13. Emery CF, Olson KL, Bodine A, et al. (2017) Dietary intake mediates the relationship of body fat to pain. Pain 158, 273-277.

14. Giugliano D, Ceriello A \& Esposito K (2006) The effects of diet on inflammation: emphasis on the metabolic syndrome. J Am Coll Cardiol 48, 677-685.

15. Nelson AD \& Camilleri M (2015) Chronic opioid induced constipation in patients with nonmalignant pain: challenges and opportunities. Therap Adv Gastroenterol 8, 206-220.

16. Srebro D, Vučković S, Milovanović A, et al. (2016) Magnesium in pain research: state of the art. Curr Med Chem (epublication 12 December 2016).

17. Bujalska-Zadrozny M, Tatarkiewicz J, Kulik K, et al. (2017) Magnesium enhances opioid-induced analgesia - What we have learnt in the past decades? Eur J Pharm Science 99, 113-127.

18. Ledade SD, Jain SN, Darji AA, et al. (2017) Narrative writing: effective ways and best practices. Perspect Clin Res $\mathbf{8}, 58-62$.

19. Howick J, Chalmers I, Glasziou P, et al. (2017) The 2011 Oxford Centre for Evidence-Based Medicine (OCEBM) Levels of Evidence. Oxford Centre for Evidence-Based Medicine. http:// www.cebm.net/index.aspx?o=5653 (accessed January 2018).

20. Istituto Nazionale di Ricerca per gli Alimenti e la Nutrizione (INRAN) (2003) Linee guida per una sana alimentazione (Guidelines for healthy eating). http://nut.entecra.it/files/ download/linee_guida/lineeguida_intro.pdf (accessed January 2018).

21. Perry BG, Bear TL, Lucas SJ, et al. (2016) Mild dehydration modifies the cerebrovascular response to the cold pressor test. Exp Physiol 101, 135-142.

22. Bear T, Philipp M, Hill S, et al. (2016) A preliminary study on how hypohydration affects pain perception. Psychophysiology 53, 605-610.

23. Parker Heinking KP \& Kappler RE (2012) Efficacy of osteopathic manipulative treatment for low back pain in euhydrated and hypohydrated conditions: a randomized crossover trial. J Am Osteopath Assoc 112, 276-284.

24. Assmann KE, Lassale C, Andreeva VA, et al. (2015) A healthy dietary pattern at midlife, combined with a regulated energy intake, is related to increased odds for healthy aging. J Nutr 145, 2139-2145.

25. Miller ER 3rd, Erlinger TP, Sacks FM, et al. (2005) A dietary pattern that lowers oxidative stress increases antibodies to oxidized LDL: results from a randomized controlled feeding study. Atherosclerosis 183, 175-182.

26. Lopes HF, Martin KL, Nashar K, et al. (2003) DASH diet lowers blood pressure and lipid-induced oxidative stress in obesity. Hypertension 41, 422-430.

27. Erlinger TP, Miller ER 3rd, Charleston J, et al. (2003) Inflammation modifies the effects of a reduced fat lowcholesterol diet on lipids: results from the DASHsodium trial. Circulation 108, 150-154.

28. Delichatsios HK \& Welty FK (2005) Influence of the DASH diet and other low-fat, high-carbohydrate diets on blood pressure. Curr Artheroscler Rep 7, 446-454.

29. Bhupathiraju SN \& Tucker KL (2011) Greater variety in fruit and vegetable intake is associated with lower inflammation in Puerto Rican adults. Am J Clin Nutr 93, 37-46.
30. Esmaillzadeh A, Kimiagar M, Mehrabi Y, et al. (2006) Fruit and vegetable intakes, C-reactive protein, and the metabolic syndrome. Am J Clin Nutr 84, 1489-1497.

31. Oliveira A, Rodriguez-Artalejo F \& Lopes C (2009) The association of fruits, vegetables, antioxidant vitamins and fiber intake with high-sensitivity C-reactive protein: sex and body mass index interactions. Eur J Clin Nutr 63, 1345-1352.

32. Holt EM, Steffen LM, Moran A, et al. (2009) Fruit and vegetable consumption and its relation to markers of inflammation and oxidative stress in adolescents. $J$ Am Diet Assoc 109, 414-421.

33. Lührs H, Gerke T, Müller JG, et al. (2002) Butyrate inhibits NF- $\kappa B$ activation in lamina propria macrophages of patients with ulcerative colitis. Scand J Gastroenterol 37, 458-466.

34. Suzuki T \& Hara H (2011) Role of flavonoids in intestinal tight junction regulation. $J$ Nutr Biochem 22, 401-408.

35. Dickinson S, Hancock DP, Petocz P, et al. (2008) High glycaemic index carbohydrate increases nuclear factor- $\mathrm{\kappa B}$ activation in mononuclear cells of young, lean healthy subjects. Am J Clin Nutr 87, 1188-1193.

36. Ceriello A (2005) Postprandial hyperglycemia and diabetes complications: is it time to treat? Diabetes 54, 1-7.

37. Fardet A (2010) New hypotheses for the health-protective mechanisms of wholegrain cereals: what is beyond fibre? Nutr Res Rev 23, 65-134

38. Gögebakan O, Kohl A, Osterhoff MA, et al. (2011) Effects of weight loss and long-term weight maintenance with diets varying in protein and glycaemic index on cardiovascular risk factors: the Diet, Obesity, and Genes (DiOGenes) study: a randomized, controlled trial. Circulation 124, 2829-2838.

39. Ebbeling CB, Swain JF, Feldman HA, et al. (2012) Effects of dietary composition on energy expenditure during weightloss maintenance. JAMA 307, 2627-2634.

40. Tripoli E, Giammanco M, Tabacchi G, et al. (2005) The phenolic compounds of olive oil: structure, biological activity and beneficial effects on human health. Nutr Res Rev 18, 98-112.

41. Harper CR, Edwards MC \& Jacobson TA (2006) Flaxseed oil supplementation does not affect plasma lipoprotein concentration or particle size in human subjects. J Nutr 136, 2844-2848.

42. Aguilera CM, Mesa MD, Ramirez-Tortosa MC, et al. (2004) Sunflower-seed oil does not protect against LDL oxidation as virgin olive oil does in patients with peripheral vascular disease. Clin Nutr 23, 673-681.

43. Owen RW, Mier W, Giacosa A, et al. (2000) Phenolic compounds and squalene in olive oils: the concentration and antioxidant potential of total phenols, simple phenols, secoiridoids, lignans and squalene. Food Chem Toxicol 38, 647-659.

44. Owen RW, Mier W, Giacosa A, et al. (2000) Identifications of lignans as major components in the phenolic fraction of olive oil. Clin Chem 46, 976-988.

45. Owen RW, Giacosa A, Hull WE, et al. (2000) Olive-oil consumption and health: the possible role of antioxidants. Lancet Oncol 1, 107-112.

46. Bendini A, Cerretani L, Carrasco-Pancorbo A, et al. (2007) Phenolic molecules in virgin olive oils: a survey of their sensory properties, health effects, antioxidant activity and analytical methods: an overview of the last decade. Molecules 12, 1679-1719.

47. Omar SH (2010) Oleuropein in olive and its pharmacological effects. Sci Pharm 78, 133-154.

48. El SN \& Karakaya S (2009) Olive tree (Olea europaea) leaves: potential beneficial effects on human health. Nutr Rev 67, 632-638. 
49. Cicerale S, Lucas LJ \& Keast RS (2012) Antimicrobial, antioxidant and anti-inflammatory phenolic activities in extra virgin olive oil. Curr Opin Biotechnol 23, 129-135.

50. Cicerale S, Lucas L \& Keast RS (2010) Biological activities of phenolic compounds present in virgin olive oil. Int $\mathrm{J} \mathrm{Mol}$ Sci 11, 458-479.

51. Visioli F, Poli A \& Gall C (2002) Antioxidant and other biological activities of phenols from olives and olive oil. Med Res Rev 22, 65-75.

52. Hu T, He XW, Jiang JG, et al. (2014) Hydroxytyrosol and its potential therapeutic effects. J Agric Food Chem 62, $1449-1455$.

53. Omar SH (2010) Cardioprotective and neuroprotective roles of oleuropein in olive. Saudi Pharm J 18, 111-121.

54. Cicerale S, Conlan XA, Sinclair AJ, et al. (2009) Chemistry and health of olive oil phenolics. Crit Rev Food Sci Nutr 49, 218-236.

55. Beauchamp GK, Keast RS, Morel D, et al. (2005) Phytochemistry: ibuprofen-like activity in extra-virgin olive oil. Nature 437, 45-46.

56. Montedoro G, Servili M, Baldioli M, et al. (1993) Simple and hydrolyzable compounds in virgin olive oil. 3. Spectroscopic characterizations of the secoiridoid derivatives. J Agric Food Chem 41, 2228-2234.

57. Andrewes P, Busch JL, de Joode T, et al. (2003) Sensory properties of virgin olive oil polyphenols: identification of deacetoxy-ligstroside aglycon as a key contributor to pungency. J Agric Food Chem 51, 1415-1420.

58. Cicerale S, Breslin PA, Beauchamp GK, et al. (2009) Sensory characterization of the irritant properties of oleocanthal, a natural anti-inflammatory agent in extra virgin olive oils. Chem Senses 34, 333-339.

59. Sahranavard S, Kamalinejad M \& Faizi M (2014) Evaluation of anti-inflammatory and anti-nociceptive effects of defatted fruit extract of Olea europaea. Iran J Pharm Res 13, 119-123.

60. Takeda R, Koike T, Taniguchi I, et al. (2013) Double-blind placebo-controlled trial of hydroxytyrosol of Olea europaea on pain in gonarthrosis. Phytomedicine 20, 861-864.

61. Cortés Castell E, Galindo CV, Montell T, et al. (2014) Efecto sobre el neurodesarrollo y neuroprotección en pez cebra de un extracto polifenólico de huesos de aceituna (Effect on neurodevelopment and neuroprotection in zebrafish of a polyphenolic extract of olive pits). Nutr Hosp 30, 338-342.

62. Zhao J, Suyama A, Chumg H, et al. (2016) Ferulic acid enhances NO production through up regulation of argininosuccinate synthase in inflammatory human endothelial cells. Life Sci 145, 224-232.

63. Suntar IP, Akkol EK \& Baykal T (2010) Assessment of antiinflammatory and antinociceptive activities of Olea europaea L. J Med Food 13, 352-356.

64. Seaman DR (2002) The diet-induced proinflammatory state: a cause of chronic pain and other degenerative diseases? J Manipulative Physiol Ther 25, 168-179.

65. Shen J, Wilmot KA, Ghasemzadeh N, et al. (2015) Mediterranean dietary patterns and cardiovascular health. Annu Rev Nutr 35, 425-449.

66. Ozawa M, Shipley M, Kivimaki M, et al. (2017) Dietary pattern, inflammation and cognitive decline: The Whitehall II prospective cohort study. Clin Nutr 36, 506-512.

67. Nuora A, Chiang VS, Milan AM, et al. (2015) The impact of beef steak thermal processing on lipid oxidation and postprandial inflammation related responses. Food Chem 184, 57-64

68. Maroon JC \& Bost JW (2006) Omega-3 fatty acids (fish oil) as an anti-inflammatory: an alternative to nonsteroidal anti-inflammatory drugs for discogenic pain. Surg Neurol 65, 326-331.

69. Nakamoto K, Nishinaka T, Sato N, et al. (2013) Hypothalamic GPR40 signaling activated by free long chain fatty acids suppresses CFA-induced inflammatory chronic pain. PLOS ONE 8, e81563.

70. Hosseinpour-Niazi S, Mirmiran P, Fallah-Ghohroudi A, et al. (2015) Non-soya legume-based therapeutic lifestyle change diet reduces inflammatory status in diabetic patients: a randomised cross-over clinical trial. Br J Nutr 114, 213-219.

71. Salehi-Abargouei A, Saraf-Bank S, Bellissimo N, et al. (2015) Effects of non-soya legume consumption on C-reactive protein: a systematic review and meta-analysis. Nutrition 31, 631-639.

72. Martin H (2010) Role of PPAR- $\gamma$ in inflammation. Prospects for therapeutic intervention by food components. Mutat Res 690, 57-63.

73. Shir Y, Raja SN, Weissman CS, et al. (2001) Consumption of soya diet before nerve injury preempts the development of neuropathic pain in rats. Anesthesiology 95, 1238-1244.

74. Arjmandi BH, Khalil DA, Lucas EA, et al. (2004) Soya protein may alleviate osteoarthritis symptoms. Phytomedicine 11, 567-575.

75. Hooshmand S, Soung do Y, Lucas EA, et al. (2007) Genistein reduces the production of proinflammatory molecules in human chondrocytes. J Nutr Biochem 18, 609-614.

76. Stecher B (2015) The roles of inflammation, nutrient availability and the commensal microbiota in enteric pathogen infection. Microbiol Spectr 3, (epublication 11 June 2015).

77. Harmsen HJ, Raangs GC, He T, et al. (2002) Extensive set of $16 \mathrm{~S}$ rRNA-based probes for detection of bacteria in human feces. Appl Environ Microbiol 68, 2982-2890.

78. Mayer EA, Knight R, Mazmanian SK, et al. (2014) Gut microbes and the brain: paradigm shift in neuroscience. J Neurosci 34, 15490-15496.

79. Chang MC, Fan SZ, Hsiao PN, et al. (2011) Influence of morphine on host immunity. Acta Anaesthesiol Taiwan 49, 105-108.

80. Roy S, Ninkovic J, Banerjee S, et al. (2011) Opioid drug abuse and modulation of immune function: consequences in the susceptibility to opportunistic infections. $J$ Neuroimmune Pharmacol 6, 442-465.

81. Banerjee S, Sindberg G, Wang F, et al. (2016) Opioidinduced gut microbial disruption and bile dysregulation leads to gut barrier compromise and sustained systemic inflammation. Mucosal Immunol 9, 1418-1428.

82. FAO/WHO (2002) Joint FAO/WHO Working Group Report on Drafting Guidelines for the Evaluation of Probiotics in Food. London, Canada: FAO/WHO.

83. Bosscher D, Breynaert A, Pieters L, et al. (2009) Food-based strategies to modulate the composition of the intestinal microbiota and their associated health effects. J Physiol Pharmacol 60, 5-11.

84. Kapoor S (2008) Management of constipation in the elderly: emerging therapeutic strategies. World J Gastroenterol 14, 5226-5227.

85. Pei R, Martin DA, Di Marco DM, et al. (2017) Evidence for the effects of yogurt on gut health and obesity. Crit Rev Food Sci Nutr 57, 1569-1583.

86. Meng H, Ba Z, Lee Y, et al. (2017) Consumption of Bifidobacterium animalis subsp. lactis BB-12 in yogurt reduced expression of TLR-2 on peripheral blood-derived monocytes and pro-inflammatory cytokine secretion in young adults. Eur J Nutr 56, 649-661. 
87. Klein A, Friedrich U, Vogelsang H, et al. (2008) Lactobacillus acidophilus 74-2 and Bifidobacterium animalis subsp lactis DGCC 420 modulate unspecific cellular immune response in healthy adults. Eur J Clin Nutr 62, 584-593.

88. Patel S (2015) Emerging trends in nutraceutical applications of whey protein and its derivatives. J Food Sci Technol $\mathbf{5 2}$ 6847-6858.

89. Cady RJ, Hirst JJ \& Durham PL (2010) Dietary grape seed polyphenols repress neuron and glia activation in trigeminal ganglion and trigeminal nucleus caudalis. Mol Pain 6, 91.

90. Woo YJ, Joo YB \& Jung YO (2011) Grape seed proanthocyanidin extract ameliorates monosodium iodoacetate-induced osteoarthritis. Exp Mol Med 43, 561-570.

91. Zhao G, Etherton TD, Martin KR, et al. (2004) Dietary $\alpha-$ linolenic acid reduces inflammatory and lipid cardiovascular risk factors in hypercholesterolemic men and women. J Nutr 134, 2991-2997.

92. Zhao G, Etherton TD, Martin KR, et al. (2007) Dietary $\alpha-$ linolenic acid inhibits proinflammatory cytokine production by peripheral blood mononuclear cells in hypercholesterolemic subjects. Am J Clin Nutr 85, 385-391.

93. Song Y, Ridker PM, Manson JE, et al. (2005) Magnesium intake, C-reactive protein, and the prevalence of metabolic syndrome in middle-aged and older U.S. women. Diabetes Care 28, 1438-1444.

94. Shechter M, Sharir M, Labrador MJ, et al. (2000) Oral magnesium therapy improves endothelial function in patients with coronary artery disease. Circulation 102, 2353-2358.

95. Ros E, Núñez I, Pérez-Heras A, et al. (2004) A walnut diet improves endothelial function in hypercholesterolemic subjects: a randomized crossover trial. Circulation 109, 1609-1614.

96. Wells BJ, Mainous AG \& Everett CJ (2005) Association between dietary arginine and C-reactive protein. Nutrition 21, 125-130.

97. Bulló M, Juanola-Falgarona M, Hernández-Alonso P, et al. (2015) Nutrition attributes and health effects of pistachio nuts. Br J Nutr 113, S79-S93.

98. Sari I, Baltaci Y, Bagci C, et al. (2010) Effect of pistachio diet on lipid parameters, endothelial function, inflammation, and oxidative status: a prospective study. Nutrition 26, 399-404.

99. Faintuch J, Horie LM, Barbeiro HV, et al. (2007) Systemic inflammation in morbidly obese subjects: response to oral supplementation with $\alpha$-linolenic acid. Obes Surg 17, 341-347.

100. Imaeda N, Tokudome $\mathrm{Y}$, Ikeda $\mathrm{M}$, et al. (1999) Foods contributing to absolute intake and variance in intake of selected vitamins, minerals and dietary fiber in middle-aged Japanese. J Nutr Sci Vitaminol 45, 519-532.

101. Chang D (2004) Effect of pumpkin distillable subject on lipid peroxidation and the activity of antioxidative enzyme induced by Plumbum in mouse [article in Chinese]. Chin J Clin Rehabil 8, 4378-4379.

102. Fahim AT, Abd-el Fattah AA, Agha AM, et al. (1995) Effect of pumpkin-seed oil on the level of free radical scavengers induced during adjuvant-arthritis in rats. Pharmacol Res 31, 73-79.

103. Oliviero F, Spinella P, Fiocco U, et al. (2015) How the Mediterranean diet and some of its components modulate inflammatory pathways in arthritis. Swiss Med Wkly 145, w14190.

104. Casas R, Sacanella E \& Estruch R (2014) The immune protective effect of the Mediterranean diet against chronic low-grade inflammatory diseases. Endocr Metab Immune Disord Drug Targets 14, 245-254.
105. Lakhan SE, Ford CT \& Tepper D (2015) Zingiberaceae extracts for pain: a systematic review and meta-analysis. Nutr J 14, 50.

106. Hu X, Huang F, Szymusiak M, et al. (2016) PLGA-curcumin attenuates opioid-induced hyperalgesia and inhibits spinal CaMKII $\alpha$. PLOS ONE 11, e0146393.

107. Salas MM, Cheppudira BP, Fowler M, et al. (2014) Analgesic and anti-inflammatory properties of curcumin: application for burn wounds. In Curcumin: Synthesis, Emerging Role in Pain Management and Health Implications, pp 255-280 [DL Pouliquen, editor]. New York: Nova Biomedical.

108. Chopra A, Saluja M, Tillu G, et al. (2013) Ayurvedic medicine offers a good alternative to glucosamine and celecoxib in the treatment of symptomatic knee osteoarthritis: a randomized, double-blind, controlled equivalence drug trial. Rheumatology (Oxford) 52, 1408-1417.

109. Vriens J, Nilius B \& Vennekens R (2008) Herbal compounds and toxins modulating TRP channels. Curr Neuropharma$\mathrm{col}$ 6, 79-96.

110. Semwal RB, Semwal DK, Combrinck S, et al. (2015) Gingerols and shogaols: important nutraceutical principles from ginger. Phytochemistry 117, 554-568.

111. Dedov VN, Tran VH, Duke CC, et al. (2002) Gingerols: a novel class of vanilloid receptor (VR1) agonists. $\mathrm{Br} \mathrm{J}$ Pharmacol 137, 793-798.

112. Klauke AL, Racz I, Pradier B, et al. (2014) The cannabinoid $\mathrm{CB}^{2}$ receptor-selective phytocannabinoid $\beta$-caryophyllene exerts analgesic effects in mouse models of inflammatory and neuropathic pain. Eur Neuropsychopharmacol 24, 608-620.

113. Treede I, Braun A, Sparla R, et al. (2007) Anti-inflammatory effects of phosphatidylcholine. J Biol Chem 282, 27155-27164.

114. Treede I, Braun A, Jeliaskova P, et al. (2009) TNF- $\alpha-$ induced up-regulation of pro-inflammatory cytokines is reduced by phosphatidylcholine in intestinal epithelial cells. BMC Gastroenterol 9, 53.

115. Andersen CJ (2015) Bioactive egg components and inflammation. Nutrients 7, 7889-7913.

116. Ballesteros MN, Valenzuela F, Robles AE, et al. (2015) One egg per day improves inflammation when compared to an oatmeal-based breakfast without increasing other cardiometabolic risk factors in diabetic patients. Nutrients $\mathbf{7}$, 3449-3463.

117. Drehmer M, Pereira MA, Schmidt MI, et al. (2016) Total and full-fat, but not low-fat, dairy product intakes are inversely associated with metabolic syndrome in adults. J Nutr $\mathbf{1 4 6}$, 81-89.

118. Bounous G, Batist G \& Gold P (1991) Whey proteins in cancer prevention. Cancer Lett 57, 91-94.

119. Schmidt A, Petry N, Walther B, et al. (2015) Inflammatory and metabolic responses to high-fat meals with and without dairy products in men. Br J Nutr 113, 1853-1861.

120. Demmer E, Van Loan MD, Rivera N, et al. (2016) Consumption of a high-fat meal containing cheese compared with a vegan alternative lowers postprandial C-reactive protein in overweight and obese individuals with metabolic abnormalities: a randomised controlled cross-over study. J Nutr Sci 5, e9.

121. Dugan CE, Aguilar D, Park YK, et al. (2016) Dairy consumption lowers systemic inflammation and liver enzymes in typically low-dairy consumers with clinical characteristics of metabolic syndrome. J Am Coll Nutr 35, 255-261.

122. Bordoni A, Danesi F, Dardevet D, et al. (2017) Dairy products and inflammation: a review of the clinical evidence. Crit Rev Food Sci Nutr 57, 2497-2525. 
123. Rocha DM, Caldas AP, Oliveira LL, et al. (2016) Saturated fatty acids trigger TLR4-mediated inflammatory response. Atherosclerosis 244, 211-215.

124. Van Meji LE \& Mensink RP (2010) Effects of low-fat dairy consumption on markers of low-grade systemic inflammation and endothelial function in overweight and obese subjects: an intervention study. Br J Nutr 104, 1523-1527.

125. Giacosa A, Barale R, Bavaresco L, et al. (2016) Mediterranean way of drinking and longevity. Crit Rev Food Sci Nutr 56, 635-640.

126. Giacosa A, Adam-Blondon AF, Baer-Sinnott S, et al. (2012) Alcohol and wine in relation to cancer and other diseases. Eur J Cancer Prev 21, 103-108.

127. Kida Y \& Goligorsky MS (2015) Sirtuins, cell senescence, and vascular aging. Can J Cardiol 32, 634-641.

128. Middleton E \& Kandaswami C (1992) Effects of flavonoids on immune and inflammatory cell functions. Biochem Pharmacol 43, 1167-1179.

129. Middleton E Jr (1998) Effect of plant flavonoids on immune and inflammatory cell function. Adv Exp Med Biol 439, 175-182.

130. Tunon MJ, Garcia-Mediavilla MV, Sanchez-Campos S, et al. (2009) Potential of flavonoids as antiinflammatory agents: modulation of pro-inflammatory gene expression and signal transduction pathways. Curr Drug Metab 10, 256-271.

131. Manthey JA (2000) Biological properties of flavonoids pertaining to inflammation. Microcirculation 7, S29-S34.

132. Grannados-Soto V, Argulles CF \& Ortiz MI (2002) The peripheral antinociceptive effect of resveratrol is associated with activation of potassium channels. Neuropharmacology 43, 917-923.

133. Kim HI, Kim TH \& Song JH (2005) Resveratrol inhibits $\mathrm{Na}^{+}$ currents in rat dorsal root ganglion neurons. Brain Res 1045, 134-141.

134. Liew R, Stagg MA, MacLeod KT, et al. (2005) The red wine polyphenol, resveratrol, exerts acute direct action on guinea-pig ventricular myocytes. Eur J Pharmacol 519, $1-8$.

135. Gao ZB \& Hu GY (2005) Trans-resveratrol, a red wine ingredient, inhibits voltage-activated potassium currents in rat hippocampal neurons. Brain Res 1056, 68-75.

136. Yu L, Wang S, Kogure Y, et al. (2013) Modulation of TRP channels by resveratrol and other stilbenoids. Mol Pain 9, 3 .

137. Kwan KY, Glazer JM, Corey DP, et al. (2009) TRPA1 modulates mechano transduction in cutaneous sensory neurons. J Neurosci 29, 4808-4819.

138. Gao ZB, Chen XQ \& Hu GY (2006) Inhibition of excitatory synaptic transmission by trans-resveratrol in rat hippocampus. Brain Res 1111, 41-47.

139. Takehana S, Sekiguchi K, Inoue M, et al. (2016) Systemic administration of resveratrol suppress the nociceptive neuronal activity of spinal trigeminal nucleus caudalis in rats. Brain Res Bull 120, 117-122.

140. Fields E (2008) History of modified-release morphine and opioid/antagonist combinations. https://www.slide serve.com/jacob/history-of-modified-release-morphine-andopioidantagonist (accessed January 2018).

141. Carson S, Thakurta S, Low A, et al. (2011) Drug Class Review: Long-Acting Opioid Analgesics: Final Update 6 Report. Portland, OR: Oregon Health and Science University.

142. Fiske WD, Jobes J, Xiang Q, et al. (2012) The effects of ethanol on the bioavailability of oxymorphone extendedrelease tablets and oxymorphone crush-resistant extendedrelease tablets. J Pain 13, 90-99.
143. Sathyan G, Sivakumar K \& Thipphawong J (2008) Pharmacokinetic profile of a 24-hour controlled-release OROS formulation of hydromorphone in the presence of alcohol. Curr Med Res Opin 24, 297-305.

144. Johnson FK, Ciric S, Boudriau S, et al. (2012) Effects of alcohol on the pharmacokinetics of morphine sulfate and naltrexone hydrochloride extended release capsules. J Clin Pharmacol 52, 747-756.

145. Hakkinen M, Launiainen T, Vuori E, et al. (2012) Comparison of fatal poisonings by prescription opioids. Forensic Sci Int 222, 327-331.

146. Webster LR, Cochella S, Dasgupta N, et al. (2011) An analysis of the root causes for opioid-related overdose deaths in the United States. Pain Med 12, S26-S35.

147. Ali NA, Marshall RW, Allen EM, et al. (1985) Comparison of the effects of therapeutic doses of meptazinol and a dextropropoxyphene/paracetamol mixture alone and in combination with ethanol on ventilatory function and saccadic eye movements. Br J Clin Pharmacol 20, 631-637.

148. Saunders KW, Von Korff M, Campbell CI, et al. (2012) Concurrent use of alcohol and sedatives among persons prescribed chronic opioid therapy: prevalence and risk factors. J Pain 13, 266-275.

149. Wenghofer EF, Wilson L, Kahan M, et al. (2011) Survey of Ontario primary care physicians' experiences with opioid prescribing. Can Fam Physician 57, 324-332.

150. Weathermon R \& Crabb DW (1999) Alcohol and medication interactions. Alcohol Res Health 23, 40-54.

151. Defagó MD, Elorriaga N, Irazola VE, et al. (2014) Influence of food patterns on endothelial biomarkers: a systematic review. J Clin Hypertens (Greenwich) 16, 907-913.

152. Lopez-Garcia E, Schulze MB, Fung TT, et al. (2004) Major dietary patterns are related to plasma concentrations of markers of inflammation and endothelial dysfunction. $A m J$ Clin Nutr 80, 1029-1035.

153. Nettleton JA, Steffen LM, Mayer-Davis EJ, et al. (2006) Dietary patterns are associated with biochemical markers of inflammation and endothelial activation in the Multi-Ethnic Study of Atherosclerosis (MESA). Am J Clin Nutr 83, 1369-1379.

154. Katz DL, Doughty K \& Ali A (2011) Cocoa and chocolate in human health and disease. Antioxid Redox Signal 15, 2779-2811.

155. di Giuseppe R, Di Castelnuovo A, Centritto F, et al. (2008) Regular consumption of dark chocolate is associated with low serum concentrations of C-reactive protein in a healthy Italian population. $J$ Nutr 138, 1939-1945.

156. Thomas CM \& Campbell P (2015) Vitamin D supplementation for pain. US Pharm 40, 43-46.

157. McCabe PS, Pye SR, Beth JM, et al. (2016) Low vitamin D and the risk of developing chronic widespread pain: results from the European male ageing study. BMC Musculoskelet Disord 17, 32.

158. Costan AR, Vulpoi C \& Mocanu V (2014) Vitamin D fortified bread improves pain and physical function domains of quality of life in nursing home residents. J Med Food 17, 625-631.

159. Von Kanel R, Müller-Hartmannsgruber V, Kokinogenis G, et al. (2014) Vitamin D and central hypersensitivity in patients with chronic pain. Pain Med 15, 1609-1618.

160. Haroon M \& Fitzgerald O (2012) Vitamin D and its emerging role in immunopathology. Clin Rheumatol 31, 199-202.

161. Shipton EE \& Shipton EA (2015) Vitamin D deficiency and pain: clinical evidence of low levels of vitamin D and supplementation in chronic pain states. Pain Ther $\mathbf{4}$, $67-87$. 
162. Straube S, Derry S \& Straube C (2015) Vitamin D for the treatment of chronic painful conditions in adults. Cochrane Database Syst Rev, issue 5, CD007771.

163. Ghazanfari S, Imenshahidi M, Etemad L, et al. (2014) Effect of cyanocobalamin (vitamin $\mathrm{B}_{12}$ ) in the induction and expression of morphine tolerance and dependence in mice. Drug Res 64, 113-117.

164. Hosseinzadeh H, Moallem SA, Moshiri M, et al. (2012) Antinociceptive and anti-inflammatory effects of cyanocobalamin (vitamin $\mathrm{B}_{12}$ ) against acute and chronic pain and inflammation in mice. Arzneimittelforschung 62, 324-329.

165. Chiu CK, Low TH, Tey YS, et al. (2011) The efficacy and safety of intramuscular injections of methylcobalamin in patients with chronic nonspecific low back pain: a randomized controlled trial. Singapore Med J 52, 868-873.

166. Freitas RD, Costa KM, Nicoletti NF, et al. (2016) Omega-3 fatty acids are able to modulate the painful symptoms associated to cyclophosphamide-induced-hemorrhagic cystitis in mice. J Nutr Biochem 27, 219-232.

167. Wagner K, Vito S, Inceoglu B, et al. (2014) The role of long chain fatty acids and their epoxide metabolites in nociceptive signaling. Prostaglandins Other Lipid Mediat 113-115, 2-12.

168. Escudero GE, Romañuk CB, Toledo ME, et al. (2015) Analgesia enhancement and prevention of tolerance to morphine: beneficial effects of combined therapy with omega-3 fatty acids. J Pharm Pharmacol 67, 1251-1262.

169. Boe C \& Vangsness T (2015) Fish oil and osteoarthritis: current evidence. Am J Orthop 44, 302-305.

170. Stanghellini V, Bellacosa L \& Cogliandro R (2013) Fiber and macrogol in the therapy of chronic constipation. Minerva Gastroenterol Dietol 59, 217-230.

171. Slavin JL (2008) Position of the American Dietetic Association: health implications of dietary fiber. J Am Diet Assoc 108, 1716-1731.

172. Longstreth GF, Thompson WG, Chey WD, et al. (2006) Functional bowel disorders. Gastroenterology 130, 1480-1491.

173. Reimer K, Hopp M, Zenz M, et al. (2009) Meeting the challenges of opioid-induced constipation in chronic pain management - a novel approach. Pharmacology 83, $10-17$.

174. Davis MP (2005) The opioid bowel syndrome: a review of pathophysiology and treatment. J Opioid Manag 1, 153-161.

175. Holzer P (2007) Treatment of opioid-induced gut dysfunction. Expert Opin Investig Drugs 16, 181-194.

176. Trinkley KE, Sill BE, Porter K, et al. (2015) Prescribing patterns for outpatient treatment of constipation, irritable bowel syndrome-related constipation, and opioid-induced constipation: a retrospective cross-sectional study. J Manag Care Pharm 21, 1077-1087.

177. Wan Y, Corman S, Gao X, et al. (2015) Economic burden of opioid-induced constipation among long-term opioid users with noncancer pain. Am Health Drug Benefits 8, 93-102.

178. Gaertner J, Siemens W, Camilleri M, et al. (2015) Definitions and outcome measures of clinical trials regarding opioidinduced constipation: a systematic review. J Clin Gastroenterol 49, 9-16.

179. Jones R, Prommer E \& Backstedt D (2015) Naloxegol: a novel therapy in the management of opioid-induced constipation. Am J Hosp Palliat Care 33, 875-880.

180. Kane-Gill SL, Rubin EC, Smithburger PL, et al. (2014) The cost of opioid-related adverse drug events. J Pain Palliat Care Pharmacother 28, 282-293.

181. Candrilli SD, Davis KL \& Iyer S (2009) Impact of constipation on opioid use patterns, health care resource utilization, and costs in cancer patients on opioid therapy. J Pain Palliat Care Pharmacother 23, 231-241.

182. Addington-Hall J, Altmann D \& McCarthy M (1998) Which terminally ill cancer patients receive hospice in-patient care? Soc Sci Med 46, 1011-1016.

183. McMillan SC \& Tittle M (1995) A descriptive study of the management of pain and pain-related side effects in a cancer center and a hospice. Hosp J 10, 89-108.

184. Tittle M \& McMillan SC (1994) Pain and pain-related side effects in an ICU and on a surgical unit: nurses' management. Am J Crit Care 3, 25-30.

185. Addington-Hall JM, MacDonald LD, Anderson HR, et al. (1991) Dying from cancer: the views of the bereaved family and friends about the experiences of terminally ill patients. Palliat Med 5, 207-214.

186. Walsh TD (1984) Oral morphine in chronic cancer pain. Pain 18, 1-11.

187. Vainio A \& Auvinen A (1996) Prevalence of symptoms among patients with advanced cancer: an international collaborative study. J Pain Symptom Manage 12, 3-10.

188. Donnelly S, Walsh D \& Rybicki L (1995) The symptoms of advanced cancer: identification of clinical and research priorities by assessment of prevalence and severity. J Palliat Care 11, 27-32.

189. Weitzner MA, Moody LN \& McMillan SC (1997) Symptom management issues in hospice care. Am J Hosp Palliat Care 14, 190-195.

190. McMillan SC (2002) Presence and severity of constipation in hospice patients with advanced cancer. Am J Hosp Palliat Care 19, 426-430.

191. McMillan SC \& Weitzner M (2000) How problematic are various aspects of quality of life in patients with cancer at the end of life? Oncol Nurs Forum 27, 817-823.

192. Barros-Neto JA, Souza-Machado A, Kraychete DC, et al. (2010) Comprometimento da integridade intestinal na fibromialgia e sindrome dolorosa miofascial: uma revisão (Impairment of intestinal integrity in fibromyalgia and myofascial pain syndrome: a review). Rev Ciênc Méd Biol 10, 246-253.

193. McMillan SC \& Small BJ (2002) Symptom distress and quality of life in patients with cancer newly admitted to hospice homecare. Oncol Nurs Forum 29, 1421-1428.

194. Prichard D, Norton C \& Bharucha AE (2016) Management of opioid-induced constipation. Br J Nurs 25, S4-S11.

195. Nelson AD \& Camilleri M (2016) Opioid-induced constipation: advances and clinical guidance. Ther Adv Chronic Dis 7, 121-134.

196. Stannard C (2016) Opioids and chronic pain: using what we know to change what we do. Curr Opin Support Palliat Care 10, 129-136.

197. Kurz A \& Sessler DI (2003) Opioid-induced bowel dysfunction: pathophysiology and potential new therapies. Drugs 63, 649-671.

198. Portenoy RK \& Derby S (1997) Assessment and management of opioid-induced constipation. In Topics in Palliative Care, vol. 1, pp. 95-112 [RK Portenoy and E Bruera, editors]. New York: Oxford University Press.

199. Robinson CB, Fritch M, Hullett L, et al. (2000) Development of a protocol to prevent opioid-induced constipation in patients with cancer: a research utilization project. Clin J Oncol Nurs 4, 79-84.

200. Mounsey A, Raleigh M \& Wilson A (2015) Management of constipation in older adults. Am Fam Physician 92, 500-504.

201. Niwa T, Nakao M, Hoshi S, et al. (2002) Effect of dietary fiber on morphine-induced constipation in rats. Biosci Biotechnol Biochem 66, 1233-1240. 
202. Li Y, Zong Y, Qi J, et al. (2011) Prebiotics and oxidative stress in constipated rats. J Pediatr Gastroenterol Nutr $\mathbf{5 3}$, $447-452$

203. National Cancer Institute (2017) Gastrointestinal Complications (PDQ®)-Health Professional Version. http://www. cancer.gov/cancertopics/pdq/supportivecare/gastrointestinalcomplications/Healthprofessional (accessed January 2018).

204. Fraga CG (2005) Relevance, essentiality and toxicity of trace elements in human health. Mol Aspects Med 26, 235-244.

205. McCall KA, Huang C-C \& Fierke CA (2005) Function and mechanism of zinc metalloenzymes. ASNS 26, 235-244.

206. Osredkar J \& Sustar N (2011) Copper and zinc, biological role and significance of copper/zinc imbalance. J Clin Toxicol S3, 001

207. Dhawan DK \& Chadha VD (2010) Zinc: a promising agent in dietary chemoprevention of cancer. Indian J Med Res 132, 676-682.

208. Bonaventura P, Benedetti G, Albaredè F, et al. (2015) Zinc and its role in immunity and inflammation. Autoimmun Rev 14, 277-285.

209. Wong CP, Rinaldi NA \& Ho E (2015) Zinc deficiency enhanced inflammatory response by increasing immune cell activation and inducing IL6 promoter demethylation. Mol Nutr Food Res 59, 991-999.

210. Liu T, Walker JS \& Tracey DJ (1999) Zinc alleviates thermal hyperalgesia due to partial nerve injury. Neuroreport 10, 645-649.

211. Matsunami M, Kirishi S, Okui T, et al. (2011) Chelating luminal zinc mimics hydrogen sulfide-evoked colonic pain in mice: possible involvement of T-type calcium channels. Neuroscience 181, 257-264.
212. Nozaki C, Vergnano AM, Filliol D, et al. (2015) Zinc alleviates pain through high-affinity binding to the NMDA receptor NR2A subunit. Nat Neurosci 14, 1017-1022.

213. Kesmati M \& Torabi M (2014) Interaction between analgesic effect of nano and conventional size of zinc oxide and opioidergic system activity in animal model of acute pain. Basic Clin Neurosci 5, 80-87.

214. Fairweather-Tait SJ, Bao J, Broadley MR, et al. (2011) Selenium in human health and disease. Antioxid Redox Signal 4, 1337-1338.

215. Rayman MP (2009) Selenoproteins and human health: insights from epidemiological data. Biochim Biophys Acta 1790, 533-540.

216. Burk RF (2002) Selenium, an antioxidant nutrient. Nutr Clin Care 5, 75-79.

217. Tinggi U (2008) Selenium: its role as antioxidant in human health. Environ Health Prev Med 13, 102-108.

218. Mattmiller SA, Bradley A, Carlson, et al. (2013) Regulation of inflammation by selenium and selenoproteins: impact on eicosanoid biosynthesis. J Nutr Sci 2, e28.

219. Bleys J, Navas-Acien A \& Guallar E (2008) Serum selenium levels and all-cause, cancer, and cardiovascular mortality among US adults. Arch Intern Med 168, 404-410.

220. Barros-Neto JA, Souza-Machado A \& Kraychete DC (2016) Selenium and zinc status in chronic myofascial pain: serum and erythrocyte concentrations and food intake. PLOS ONE 11, e 0164302.

221. Ciubotariu D, Ghiciuc CM \& Lupusoru CE (2015) Zinc involvement in opioid addiction and analgesia - should zinc supplementation be recommended for opioid-treated persons? Subst Abuse Treat Prev Policy 10, 29. 